\title{
ICONOGRAFÍA DE LA MODERNIZACIÓN EDUCATIVA EN ESPAÑA EN EL CONTEXTO DE LA LEY GENERAL DE EDUCACIÓN DE 1970*
}

\author{
Iconography of the modernization of the Spanish education \\ system in the context of the General Education Law of 1970
}

\section{Sara González Gómez ${ }^{\mathfrak{1}}$ y Xavier Motilla Salas ${ }^{\&}$}

Fecha de recepción: 29/05/2017 • Fecha de aceptación: 30/08/2017

Resumen. La Ley General de Educación (LGE) de 1970 supuso en España la introducción de un nuevo marco legislativo de carácter heterogéneo en el que convivieron, por un lado, la tradición de la política educativa del régimen y, por otro, un carácter renovador e innovador del sistema, inspirado en las reformas educativas que a nivel internacional venían desarrollándose desde la década de los sesenta del siglo pasado. El artículo que aquí se presenta tiene como objetivo fundamental comprobar si la modernización educativa que se puso en marcha en el contexto de la reforma de 1970 se vio o no reflejada en el discurso visual generado por el franquismo. Tratamos de averiguar en qué medida el régimen habría querido transmitir, con fines propagandísticos, una imagen de modernización educativa, en los medios nacionales y extranjeros, y qué niveles educativos se emplearon para instrumentalizar esa iconografía a través del análisis de la colección de fotografías que con fines de difusión recopiló la Agencia EFE.

Palabras clave: Fotografía; Propaganda; Educación; Ley General de Educación (1970); Agencia EFE

\footnotetext{
* Artículo realizado en el marco del proyecto I+D+I La fotografía publicada como representación de los cambios y las continuidades en la cultura escolar (1900-1970) (EDU2014-52498-C2-2-P), financiado por el Programa estatal de fomento de la investigación científica y técnica de excelencia, subprograma estatal de generación del conocimiento, en la convocatoria del 2014 (Ministerio de Economía, Industria y Competitividad y la Agencia Española de Investigación, fondos FEDER y Unión Europea). ${ }^{£}$ Departamento de Pedagogía y Didácticas Específicas. Facultad de Educación. GEDHE/IRIE, Universitat de les Illes Balears. Ed. Guillem Cifre de Colonya, cra. de Valldemossa, km. 7,5, 07122, Palma. España. sara.gonzalez@uib.es

\& Departamento de Pedagogía y Ddidácticas Específicas. Facultad de Educación. GEDHE/IRIE, Universitat de les Illes Balears. Ed. Guillem Cifre de Colonya, cra. de Valldemossa, km. 7,5, 07122, Palma. España.xavier.motilla@uib.es
}

Cómo citar este artículo: González Gómez, Sara y Xavier Motilla Salas. «Iconografía de la modernización educativa en España en el contexto de la Ley General de Educación de 1970». Historia y Memoria de la Educación 8 (2018): 449-487. 
Abstract. Spain's General Education Law (Ley General de Educación) of 1970 meant the introduction of a new heterogeneous legislative framework that combined, on the one hand, the traditional educational policies of the government, and on the other, a renewed, innovative ethos inspired by the international educational reforms that had been taking place since the 1960s. The main objective of this article is to analyze whether or not the modernization of the Spanish education system that began in the context of the 1970 reform could be seen in the visual discourse created by the Franco regime. We try to ascertain to what extent the government would have wanted to transmit, for propagandistic purposes, an image of the modernization of the education system in national and foreign media, and what levels of education were used to exploit this iconography through an analysis of the collection of photographs compiled for dissemination by the Spanish news agency Agencia EFE.

Keywords: Photography; Propaganda; Education; General education law (1970); Agencia EFE

\section{INTRODUCCIÓN}

La Ley General de Educación (LGE) de 1970 venía «precedida como pocas del clamoroso deseo popular de dotar a nuestro país de un sistema educativo más justo, más eficaz, más acorde con las aspiraciones y con el ritmo dinámico y creador de la España actual» (Preámbulo de la Ley 14/1970, de 4 de agosto, General de Educación y Financiamiento de la Reforma Educativa, BOE, n. ${ }^{\circ} 187$, de 6 de agosto de 1970). Sin embargo, la nueva Ley no escapó a una importante controversia en su gestación, promulgación y posterior proceso de implementación. Han sido numerosos los profesionales que han coincidido en afirmar que, pese a todo, la LGE de 1970 constituyó un punto de inflexión en la evolución del sistema educativo español. Pero probablemente, el cambio no se produjo en aquel preciso instante, pues las medidas y el viraje en la orientación de las decisiones en materia de política educativa que venían operándose previamente hicieron tributaria a la década de los sesenta de una concepción desarrollista en la que la educación jugó un papel fundamental. ${ }^{1}$ Así, sin perder de vista los cambios emprendidos durante los años sesenta, el objetivo fundamental del presente artículo es comprobar si la modernización educativa que se puso en marcha en el marco de la reforma de

\footnotetext{
${ }^{1}$ Manuel de Puelles Benítez, «Tecnocracia y política en la reforma educativa de 1970», Revista de Educación. La Ley General de Educación veinte años después, n. ${ }^{\circ}$ extraordinario (1992): 13-29.
} 
1970, a través de la reapropiación particular que los técnicos españoles vinculados a los sectores aperturistas del régimen hicieron de las ideas, métodos y discursos de los organismos internacionales, así como de las teorías del capital humano, ${ }^{2}$ se verá asimismo reflejada en la iconografía que de esa modernización se hizo en diferentes medios de prensa escrita y, en este caso concreto de estudio, en la colección de fotografías que con fines de información periodística y difusión propagandística recopiló la Agencia EFE. En esencia, ¿Qué imagen o discurso iconográfico educativo, consciente o inconscientemente, se promovió a través de la Agencia EFE mediante las fotografías tomadas para su posterior uso en los medios de comunicación? Se trataría de averiguar en qué medida el régimen habría querido transmitir, con fines propagandísticos, una imagen de modernización educativa, en los medios nacionales y extranjeros, en los inicios de la implementación de la LGE y qué niveles educativos se emplearon para instrumentalizar esa iconografía modernizadora.

Debemos tener en cuenta, en este sentido, que el franquismo canalizó el control informativo y propagandístico del régimen a través de la creación de la agencia de prensa EFE. Las agencias de prensa, encargadas de recoger información en formato texto o visual de un territorio determinado para ofrecerla a sus abonados, fueron un modelo de empresa que se consolidó a partir de la segunda mitad del siglo XIX. Sucesivamente fueron apareciendo las principales agencias de prensa a nivel internacional: la francesa Agencia Havas, en 1835, antecesora de France Presse, la estadounidense Associated Press, en 1848, la alemana Wolff, en 1849 y la británica Reuter, en $1851 .^{3}$ En España, la primera fue la Agencia Fabra, creada en 1919, que mantuvo una estrecha dependencia de la francesa Havas hasta que se convirtió en el embrión de la Agencia EFE, creada a principios de 1939 por Manuel Aznar Zubigaray y Ramón Serrano Suñer quien, muy preocupado por la mala imagen exterior que tenían los nacionales, fue su máximo impulsor. Según Víctor Olmos, ${ }^{4}$ su creación

\footnotetext{
${ }^{2}$ Cecilia Cristina Milito Barone y Tamar Groves, «¿Modernización o democratización? La construcción de un nuevo sistema educativo entre el tardofranquismo y la democracia», Bordón 65, no. 4 (2013): 143.

${ }^{3}$ Vid. Armand Mattelart, La comunicación-mundo: historia de las ideas y de las estrategias (Madrid: Siglo xxI, 1996), y Jacques Wolf, «Structure, fonctionnement et évolution du marché international des nouvelles. Les agences de presse de 1835 à 1934», Revue économique 42, no. 3 (1991): 575-601.

${ }^{4}$ Víctor Olmos, Historia de la Agencia EFE. El mundo en español (Madrid: Espasa Calpe, 1997), 37-58.
} 
se fue gestando a lo largo de los años de la Guerra Civil para canalizar la información que el régimen franquista quería difundir, especialmente en el extranjero, y para contrarrestar la mejor organización de la distribución internacional de noticias que tenía el gobierno de la República. La Agencia EFE fue creada como una sociedad anónima para tener mayor credibilidad en el contexto internacional que una entidad de carácter oficial y poder situarse al mismo nivel que otras agencias internacionales. En realidad, los impulsores fueron personas muy cercanas a los militares sublevados que acabarían ganando la guerra y estableciendo la dictadura franquista. A lo largo de toda la dictadura, la agencia siguió bajo la influencia de los intereses informativos del régimen, aunque experimentó con los años un importante proceso de modernización y de progresiva apertura internacional. Como ha destacado José Miguel Delgado, de forma más contundente en las primeras etapas del franquismo, pero también a lo largo de toda la etapa dictatorial, la Agencia EFE se convirtió en pieza fundamental del poderoso sistema de control informativo y propagandístico del régimen. ${ }^{5}$

En la actualidad, la fototeca digital de la Agencia EFE incluye numerosas fotografías relacionadas con temas educativos, formales y no formales, que constituyen a su vez un muestrario de los documentos fotográficos a disposición de los medios de comunicación impresos de la época. Creada en 1998, la fototeca de la Agencia EFE pretendió responder a la necesidad de ordenar, clasificar y garantizar la localización y conservación de un fondo fotográfico creciente. ${ }^{6}$ Hay que tener en cuenta que las fotografías albergadas en su archivo y las que se pueden consultar hoy en día a través de su fototeca digital representan testimonios recogidos para su posterior uso en la prensa. Como han señalado Bernat Sureda y Gabriel Barceló, la fototeca digital de la Agencia EFE nos ofrece un conjunto numeroso de fotografías que ejemplifican cómo se fue cons-

\footnotetext{
${ }^{5}$ José Miguel Delgado Idarreta, "Prensa y propaganda bajo el franquismo», en Centros y periferias: prensa, impresos y territorios en el mundo hispánico contemporáneo: homenaje a Jacqueline Covo-Maurice, eds. Nathalie Ludec y Françoise Dubosquet Lairys (Paris: Pilar, 2004), 221.

${ }^{6}$ Vid. Paloma Rupérez Rubio, «El Archivo Gráfico de la Agencia EFE. Transición de un sistema manual a un sistema digitalizado: un análisis de la imagen», Cuadernos de documentación multimedia 6-7 (1998). http://pendientedemigracion.ucm.es/info/multidoc/multidoc/revista/cuad6-7/efe.htm, ( consultado 17-04-2017) y Concha Tejedor, «El papel de los archivos en la sociedad de la información. El centro de documentación de la Agencia EFE», en Documentación e poder na sociedade da información: o papel dos arquivos e os observatorios de comunicación, eds. Xosé López García y Rosa Aneiros Díaz (Santiago de Compostela: Consello de Cultura Gallega, 2009), 67-78.
} 
truyendo la iconografía propia del franquismo, así como de su evolución a lo largo del periodo dictatorial. En cuanto a la educación del régimen, en un clima de fuerte control ideológico de todos los medios de comunicación, la fotografía permite analizar aquellos aspectos que se quisieron resaltar públicamente sobre la educación implantada. ${ }^{7}$ Si consideramos que la fotografía no es tanto un testigo visual objetivo y neutro de lo que aconteció históricamente, sino un elemento para conformar un discurso explicativo o justificativo de la realidad, ${ }^{8}$ un conjunto tan numeroso de fotografías creadas en un marco institucional y empresarial claramente controlado y puesto al servicio de los objetivos ideológicos y propagandísticos del régimen franquista, puede ayudarnos sin duda a conocer las características de este discurso. En este sentido, concretamente, la colección de fotografías de los fondos digitalizados de la Agencia EFE sobre educación del periodo que abarca la gestación, promulgación y primeros años de implementación de la LGE nos puede permitir aproximarnos a la imagen y proyección pública que el régimen quiso promocionar sobre ella, y la supuesta modernización de la educación que debería impulsar la nueva legislación, en contraste con tiempos precedentes.

Para la elaboración de este trabajo se ha realizado una primera catalogación de las fotografías sobre educación localizadas en la fototeca digital de la Agencia EFE del periodo que abarca los años de 1970 a 1975, estableciéndose diversas categorías temáticas (véase Tabla I). De la amplia muestra localizada e inventariada se ha procedido a seleccionar aquellas que se circunscriben a los periodos de escolarización obligatorios y postobligatorios a los que la LGE afectó directamente, inventariándolas y catalogándolas según tipologías (véase Tabla II). Para establecer dichas tipologías hemos seguido trabajos previos, ${ }^{9}$ procediendo posteriormente al análisis específico de las fotografías a partir de tres niveles

\footnotetext{
${ }^{7}$ Bernat Sureda y Gabriel Barceló, «L'escola divulgada pel franquisme: el fons fotogràfic de l'Agència EFE», en Imatges de l'escola, imatge de l'educació, eds. Francisca Comas, Sara González, Xavier Motilla y Bernat Sureda (Palma: Universitat de les Illes Balears, 2014), 277-288.

${ }^{8}$ Francisca Comas, Xavier Motilla y Bernat Sureda, «Escuela y fotografía, entre el testimonio y la construcción del discurso narrativo», en Patrimonio y Etnografía de la escuela en España y Portugal durante el siglo XX. III Foro Ibérico de Museísmo Pedagógico. V Jornadas Científicas de la Sociedad Española para el Estudio del Patrimonio Histórico Educativo (SEPHE), eds. Pedro L. Moreno y Ana Sebastián (Murcia: Universidad de Murcia, CEME, SEPHE, 2012), 405-417.

${ }^{9}$ Comas, Motilla y Sureda, «Escuela y fotografía, entre el testimonio y la construcción del discurso narrativo".
} 
de aproximación - análisis de la imagen, contexto histórico e interpretación-, inspirados en buena medida en el método iconográfico de Erwin Panofsky. Este procedimiento metodológico nos ha permitido orientar la lectura del relato que presentan dichas fotografías, así como contrastar la información que aportan en relación a otras fuentes secundarias. Asimismo, hemos pretendido utilizar las fotografías, tal y como proponía Walter Benjamin, para posibilitar deconstrucciones de la historia, pues las imágenes tienen el poder de descubrir la historia incontable (del inconsciente), aportan materiales que pueden ser intemporales, manejados por el artista-historiador para desmitificar lo contado y hacer oposición política y discurso crítico al presente. ${ }^{10}$

Tabla I. Inventario y catalogación de fotografías de temática educativa de la fototeca de la Agencia EFE (1970-1975). Elaboración propia.

\begin{tabular}{|l|c|}
\hline \multicolumn{1}{|c|}{ Categoría } & N. $^{\text {o de fotografías }}$ \\
\hline Becas & 6 \\
\hline Educación artística y musical & 7 \\
\hline Educación de adultos & 5 \\
\hline Educación especial & 3 \\
\hline Educación infantil & 29 \\
\hline Educación no formal & 31 \\
\hline Escuela & 85 \\
\hline Formación profesional & 35 \\
\hline INEF & 17 \\
\hline Enseñanza media (institutos) & 5 \\
\hline Institutos de investigación & 12 \\
\hline Legislación (aprobación en Cortes) & 34 \\
\hline OJE & 24 \\
\hline Universidad & 199 \\
\hline Universidad laboral & 19 \\
\hline TOTAL & 511 \\
\hline
\end{tabular}

\footnotetext{
${ }^{10}$ Miguel A. Hernández-Navarro, Materializar el pasado: el artista como historiador (benjaminiano) (Murcia: Micromegas, 2012), 43-66, y Walter Benjamin, Discursos interrumpidos I (Buenos Aires: Taurus, 1989).
} 
Tabla II. Inventario y catalogación de fotografías de temática escolar de la fototeca de la Agencia EFE (1970-1975) por tipología. Elaboración propia.

\begin{tabular}{|l|c|c|c|c|}
\hline \multicolumn{1}{|c|}{ Tipología } & PREESCOLAR & EGB & BUP/COU & FP \\
\hline Fotografías de grupo & 1 & 7 & 0 & 0 \\
\hline Fotografías de clase & 16 & 22 & 0 & 11 \\
\hline $\begin{array}{l}\text { Fotografías de espacios y } \\
\text { edificios escolares }\end{array}$ & 0 & 4 & 1 & 3 \\
\hline $\begin{array}{l}\text { Fotografías de actividades } \\
\text { ordinarias }\end{array}$ & 6 & 10 & 0 & 9 \\
\hline $\begin{array}{l}\text { Fotografías de actividades } \\
\text { extraordinarias }\end{array}$ & 2 & 12 & 0 & 9 \\
\hline Otras & 29 & 30 & 0 & 3 \\
\hline TOTAL: 150 fotografías & & & 1 & 35 \\
\hline
\end{tabular}

En cuanto al uso de la fotografía en la historiografía educativa, hay que tener en cuenta que, durante las últimas décadas, sus diferentes posibilidades se han convertido en objeto de estudio, reflexión y debate entre un importante núcleo de investigadores. Cada vez con más frecuencia, nos encontramos con trabajos en los que las fotografías se utilizan como una fuente más de investigación que se suma a las tradicionalmente utilizadas, línea en la que el presente artículo se inscribe. Asimismo, los historiadores de la educación han pasado no sólo a utilizar la fotografía como fuente —más allá de su plano meramente ilustrativo—-, sino también a reivindicar su valor patrimonial y su preeminencia en la recuperación del recuerdo y la construcción/reconstrucción de la memoria. La bibliografía aparecida al respecto en las últimas décadas a nivel internacional en diversas revistas como Historie de l'Education, Paedagogica Historica, History of Education, Historia de la Educación o Educació i Història, entre otras, algunas de ellas con números monográficos específicos, empieza a ser abundante. ${ }^{11}$ Lejos

\footnotetext{
${ }^{11}$ Pueden destacarse, entre otros y sin ánimo de exhaustividad, como indicadores de dicho interés los precedentes publicados en 1986 en Historie de l'Education: Yves Gaulupeu, «L'historie en images à l'école primaire. Un exemple: la Révolution française dans les manuels élémentaires (1870-1970)», 30 (1986): 29-52; Serge Chassagne, "Éducation et peinture au XIX siècle: un champ iconique en friches», 30 (1986): 53-59; y Élisabeth Bassargette, «Le mouchoir illustré rouennais. Une imagerie éducative», 30 (1986): 61-66; los trabajos aportados en el número monográfico de Pedagogica Historica en 2000: Marc Depaepe y Bret Henkens, «The History of Education and the Challenge of the
} 
de apagarse el debate, las aportaciones al respecto se han ido sucediendo en los últimos años, ya en la nueva centuria, tanto a nivel internacional como en el contexto español en las principales revistas científicas histórico-educativas o de otros ámbitos. ${ }^{12}$ Asimismo, son diversos también los

Visual» 36, no. 1 (2000): 11-17; Antonio Nóvoa, «Ways of Saying, Ways of Seeingx Public Images of Teachers (19th-20th Centuries)» 36, no. 1 (2000): 21-52; Antonio Viñao, «Iconology and Education: Notes on the Iconographic Representation of Education and Related Terms» 36, no. 1 (2000): 75-92; y José F. Jiménez Trujillo, «Another View on Education: Educational Policy of the Second Republic of Spain Seen from Pictorial Humor in Satirical and Conservative Press» 36, no. 1 (2000): 427-448; o los artículos publicados en History of Education un año más tarde: Ian Grosvenor y Martin Lawn, "Ways of seeing in education and schooling: emerging historiographies» 30, no. 2 (2001): 105-108; Kate Rousmaniere, «Questioning the visual in the history of education» 30, no. 2 (2001): 109-116; Martin Lawn y Ian Grosvenor, "When in doubt, preserve”: exploring the traces of teaching and material culture in English schools» 30, no. 2 (2001): 117-127; y Catherine Burke, «Hands on history: Towards a critique of the "everyday"» 30, no. 2 (2001): 191-201.

${ }^{12}$ Eric Margolis y Jeremy Rowe, «Images of assimilation: photographs of Indian schools in Arizona», History of Education. Journal of the History of Education Society 33, no. 2 (2004): 199-230; Catherine Burke, «The body of the schoolchild in the history of education», Ib History of Education. Journal of the History of Education 36, no. 2 (2007): 165-171; Catherine Burke y Helena Ribeiro de Castro, "The school photograph: Portraiture and the art of assembling the body of the schoolchild», History of Education. Journal of the History of Education 36, n. 2 (2007): 213-226; Eric Margolis y Sheila Fram, «Caught napping: Images of surveillance, discipline and punishment on the body of the school child», History of Education. Journal of the History of Education 36, no. 2 (2007): 193-194; Ian Grosvenor, «From the "Eye of History" to "a Second Gaze": The visual archive and the marginalized in the history of education", History of Education. Journal of the History of Education 36, no. 4 (2007): 607-622; Catherine Burke y Ian Grosvenor, «The progressive image in the history of education: stories of two schools», Visual Studies 22, no. 2 (2007): 155-168; María del Mar del Pozo, «Imágenes e Historia de la Educación: construcción, reconstrucción y representación de las prácticas escolares en el aula», Historia de la Educación. Revista Interuniversitaria 25 (2006): 291-315; Francesca Comas, «Presentació: Fotografia i Història de l'Educació», Educació i Història. Revista d'història de l'educació 15 (2010): 9-15; Isabel Argerich, «Imatges fotogràfiques de temàtica educativa en col-leccions i arxius públics i privats», Educació i Història. Revista d'història de l'educació 15 (2010): 55-72; Catalina Aguiló, Maria J. Mulet y Paula Pinya, «La fotografia de temàtica escolar en arxius no especialitzats. Notes sobre fons en imatge a Mallorca", Educació i Història. Revista d'història de l'educació 15 (2010): 73-98; Marc Depaepe y Frank Simon, «Sobre el treball amb fonts: consideracions des del taller sobre història de l'educació", Educació i Història. Revista d'història de l'educació 15 (2010): 99-122; Sjaak Braster, «How (un-)useful are for understanding histories of education? About teacher centeredness and new education in Dutch primary schools: 1920-1985», Educació i Història. Revista d'història de l'educació 15 (2010): 123-148; Ian Grosvenor, «The school album: images, insights and inequalities», Educació i Història. Revista d'història de l'educació 15 (2010): 149-164; María del Mar del Pozo y Teresa Rabazas, «Imatges fotogràfiques i cultura escolar en el franquisme: una exploració de l'arxiu etnogràfic», Educació i Història. Revista d'història de l'educació 15 (2010): 165-194; Francesca Comas, Miquel March y Bernat Sureda, «Les pràctiques educatives de l'escoltisme de Mallorca durant la dictadura franquista a través de les fotografies», Educació i Història. Revista d'història de l'educació 15 (2010): 195-126; Carmen Sanchidrián, «El uso de imágenes en la investigación histórico-educativa», RIE. Revista de Investigación Educativa 29, no. 2 (2011): 295-309; Francisca Comas, Xavier Motilla y Bernat Sureda, «Iconografía y representación gráfica de las colonias escolares de la Diputación de Baleares. Una aproximación a través del análisis de las fotografías de las memorias», Revista Española de Pedagogía LXIx, 269 (2011): 445-462; Francisca Comas y Bernat Sureda, «Photography 
volúmenes, fruto de jornadas científicas y congresos o de compilaciones de trabajos de investigación previos, que han tratado específicamente el tema durante las últimas décadas. ${ }^{13}$

Este artículo se estructura en tres grandes apartados. El primero recoge, de forma sucinta, el panorama general previo a la promulgación de la LGE de 1970, haciendo un repaso por los principales hitos de carácter educativo, los cambios en la cúspide ministerial y la aprobación de medidas de carácter normativo. En el segundo se sintetizan los cambios esenciales introducidos por la LGE de 1970. Finalmente, se efectúa el estudio de la iconografía de la modernización, en el contexto de la nueva Ley de educación, a través del análisis de una muestra de fotografías pertenecientes a la fototeca de la Agencia EFE generadas en los meses previos a su promulgación y durante los primeros años de implementación, bajo el régimen franquista.

\section{LA INMEDIATA ANTESALA A LA APROBACIÓN DE LA LGE DE 1970}

Al compás de los procesos de cambio económico y social que se desencadenaron en España durante la década de los sesenta y que fueron transformando de forma progresiva el panorama general del país -con la eclosión del turismo, las masivas migraciones del campo a la ciudad, el proceso de industrialización o el incremento del comer-

\footnotetext{
and advertising of the Maria Montessori method in Spain (1911-1931)», Paedagogica Historica 48, no. 4 (2012): 571-578; Francisca Comas y Bernat Sureda, «Proposals for women's education in the magazine Feminal», History of Education \& Children Literature VIII, no. 2 (2013): 273-292; Bernat Sureda, Xavier Motilla y Francisca Comas, «La revista Feminal: fotografía y visualización de la aportación femenina a la renovación educativa en Cataluña (1907-1917)», Historia de la Educación. Revista Interuniversitaria 33 (2014): 215-230; Llorenç Gelabert y Xavier Motilla, «Imatge, formació religiosa i educació a la revista il-lustrada Lluc (1921-1973)», Educació i Història. Revista d'història de l'educació 24 (2014): 103-134; Pedro Luis Moreno, «Imágenes e historia de la educación popular: representaciones fotográficas de las Misiones Pedagógicas en la región de Murcia», Historia y Memoria de la Educación 5 (2017): 73-156.

${ }^{13}$ Vid. Marc Depaepe y Bregt Henkens (eds.), Imagine, all the education... The visual in the making of the educational space through history. Programme and abstract book of the XXth International Standing Conference for the History of Education (Leuven: ISCHE, 1998); Ulrike Mietzner, Kevin Myers y Nick Peim (eds.), Visual History. Images of Education (Bern: Peter Lang, 2005); Ian Grosvenor, Martin Lawn y Kate Rousmaniere (eds.), Silences and images. The social history of the classroom (Nova York: Peter Lang, 1999); Francesca Comas, Xavier Motilla y Bernat Sureda, Fotografia i història de l'educació. Iconografia de la modernització educativa (Palma: Lleonard Muntaner Editor, 2012); Francesca Comas, Sara González, Xavier Motilla y Bernat Sureda (eds.), Imatges de l'escola, imatge de l'educació (Palma: Universitat de les Illes Balears, 2014).
} 
cio exterior, entre otras muchas cosas-, se produjeron los primeros intentos por modernizar la arcaica política educativa del régimen. La inmersión en aquel proceso de desarrollismo económico reveló muy pronto la acuciante necesidad de efectuar una reforma profunda de un sistema educativo ahormado a partir de un modelo tradicional, entonces ya inoperante y obsoleto. Tal y como sostiene Escolano Benito, «el tradicionalismo pedagógico era incompatible con la dinámica de industrialización que iniciaba el país, que exigía una nueva escuela, más acorde con las corrientes dominantes en los países en desarrollo». ${ }^{14} \mathrm{Si}$ a ello unimos la presión ejercida por parte de determinados organismos internacionales, como la OCDE o la UNESCO — que jugaron entonces un papel fundamental al sugerir al régimen español, en diversas ocasiones y mediante diferentes informes y documentos, el viraje de su política educativa-, o la creencia firmemente extendida en las teorías del capital humano - en España, la década de los sesenta está jalonada de trabajos e informes que relacionan la educación con el desarrollo económico, y que culminan en el libro El capital humano de J. L. Romero y Amando de Miguel $^{15}$-, nada hay de extraño en que desde principios de los años sesenta del pasado siglo, en medios oficiales del franquismo, se fuera presentando una decidida apuesta por reformar el sistema educativo a favor de una enseñanza universal, obligatoria y gratuita, con igualdad de oportunidades, y que ésta fuera concebida como un imperativo para el crecimiento económico en la sociedad del desarrollo científico y técnico, y de la expansión de la producción y del consumo. ${ }^{16}$ En este sentido, el grupo de técnicos o tecnócratas que comenzaron a copar las esferas ministeriales en la década de los sesenta efectuó una asimilación o reapropiación de un discurso que ya entonces circulaba por muchos países y del que España, dadas las características de su sistema político de carácter dictatorial, se encontraba a la zaga.

Por tanto, toda esa inercia internacional de extensión y estandarización de los sistemas educativos, experimentada desde la medianía del

\footnotetext{
${ }^{14}$ Agustín Escolano Benito, «Discurso ideológico, modernización técnica y pedagógica crítica durante el franquismo», Historia de la educación: Revista interuniversitaria 8 (1989): 14.

${ }^{15}$ Fernando Gil Villa, «El estudiante como actor racional. Objeciones a la teoría del capital humano», Revista de Educación 306 (1995): 316.

${ }^{16}$ Julio Mateos, «La marcha hacia la educación tecnocrática y de masas: sociedad y educación en España (1939-1970)», Dossier Educación de Revista de Andorra 11 (2012): 59.
} 
siglo xx por países desarrollados o en vías de desarrollo, se inscribía en el marco de las teorías del capital humano ¿Qué sucedió en el caso español? Pues que con la apertura de la década de los cincuenta se vivió una breve etapa que podría caracterizarse como de «atisbo de apertura o modernización» de la política educativa —que contrasta con el mantenimiento de una situación de autarquía económica- representada por el ministerio de Joaquín Ruiz-Giménez (1951-1956). Su equipo ministerial aspiró a introducir reformas capaces de flexibilizar las férreas estructuras de la dictadura y apostó decididamente por el acercamiento a Europa. A nivel legislativo, procedió a la aprobación de la Ley de ordenación de la enseñanza media de 1953 y en el terreno universitario, con el apoyo de rectores como Laín Entralgo en Madrid y Tovar Llorente en Salamanca, procuró cambiar ligeramente la atonía de un panorama ciertamente desolador. Lo cierto es que entonces el contexto era distinto al de los primeros años del franquismo, de ahí que aquella Ley de 1953 fuera algo más sosegada y técnica, fiel a los principios del Movimiento y de la Iglesia pero, también es verdad, que con ella se inició una etapa de mayor presencia pública y secularización de la enseñanza secundaria así como un incremento de la fuerza inspectora estatal en todos los centros docentes. ${ }^{17}$

No podemos perder tampoco de referencia que hablamos de un hombre para el cual el diálogo supuso una pieza central en su modo de proceder, un hombre muy diferente a los que hasta entonces habían ocupado este cargo durante la dictadura, un sincero católico que siempre demostró un profundo respeto hacia la conciencia individual, recordado por sus Cuadernos para el diálogo, y porque, tal y como define Elías Díaz, fue «un constructor de puentes, un hombre que se tomaba muy en serio los derechos humanos, que creía y cada vez más en la libertad, la igualdad (la justicia social) y la solidaridad ${ }^{18}$, siguiendo claramente unos principios rectores muy presentes ya en la política educativa del marco europeo. Pero las desavenencias con el régimen no tardaron en hacerse sentir y la situación estudiantil acaecida en Madrid durante el mes de febrero de 1956 marcó la primera regla de juego que habría de regir la

\footnotetext{
${ }^{17}$ Leoncio Vega Gil, «Aproximación a la enseñanza secundaria durante el franquismo (1938-1967)», Historia de la Educación. Revista interuniversitaria 8 (1989): 29-44.

${ }^{18}$ Elías Díaz, De la Institución a la Constitución. Política y cultura en la España del siglo XX (Madrid: Trotta, 2009), 7.
} 
sustitución ministerial en el ámbito educativo. El proyecto aperturista en el terreno de la política educativa quedó truncado y se impuso entonces la restauración del "control perdido», volviéndose a las líneas directrices propias del sistema educativo tradicional, personificado ahora en la figura de Jesús Rubio García-Mina (1956-1962) que inauguró una etapa que podríamos caracterizar por la restauración del orden y el control, la excesiva burocracia y en la que se dieron escasas novedades en el yermo ámbito educativo.

Unos años más tarde, iniciado oficialmente en España el periodo de desarrollismo con el Plan de Estabilización del año 1959, se produjo el nombramiento de Manuel Lora Tamayo como Ministro de Educación (1962-1968), cuyo empeño se centró en la modernización de la enseñanza. Ya dentro del primer Plan de Desarrollo Económico-Social (1964-1967), en sucinta referencia a la política educativa, se mencionó que el objetivo principal en esta materia era «conseguir en breve plazo los servicios mínimos de enseñanza a todos los españoles». Ese mismo año se aprobó la Ley 27/1964, de 29 de abril, sobre ampliación del periodo de escolaridad obligatoria hasta los 14 años, entendiendo que una mejor formación básica de todos los españoles constituía un supuesto indispensable para la solución de los problemas económicos y sociales del país. Supuso aquello un pequeño avance en cuanto a la expansión de la escolaridad; de hecho, el incremento en el número de estudiantes será significativo a lo largo de esta década; pero tampoco podemos perder de referencia que la falta de medios impidió una aplicación íntegra y real de esa escolaridad y que, por otra parte, se «mantenía el clasismo que suponía superponer el Bachillerato elemental a la enseñanza primaria». ${ }^{19}$ Un año después se promulgó la Ley 169/1965, de 21 de diciembre, sobre reforma de la Enseñanza Primaria que aspiraba a ampliar, actualizar y, en ciertos aspectos técnicos, a perfeccionar la entonces vigente (promulgada en 1945), «sin modificar sustancialmente su signo y orientación, pero con auténtica y efectiva superación de contenido» (Preámbulo de la Ley 169/1965, de 21 de diciembre, sobre reforma de la Enseñanza Primaria, BOE, n. ${ }^{\circ} 306$, de 23 de diciembre de 1965). Posteriormente, aparecería la Ley 16/1967, de 8 de abril, sobre

\footnotetext{
${ }^{19}$ Félix Ortega, «Las ideologías de la reforma educativa de 1970», Revista de Educación, no. extraordinario «La Ley General de Educación veinte años después» (1992): 34.
} 
unificación del primer ciclo de la Enseñanza Media, que de nuevo aspiraba a la extensión y democratización de la enseñanza media mediante un bachillerato elemental unificado y accesible a la universalidad de la población escolar con edades comprendidas entre los 10 y los 14 años. Pocos meses después, la Orden de 4 de septiembre de 1967 aprobaría los nuevos cuestionarios para las nuevas materias de este "refundido» nivel educativo que unía en uno solo a los anteriores bachilleratos elemental y laboral.

En 1968 tomó el relevo José Luis Villar Palasí (1968-1973) como Ministro de Educación, un hombre que, inicialmente, centró toda su atención en la universidad, pero muy pronto entendió que ésta era solo «la punta del iceberg ${ }^{20}$ y que no podía desatenderse la modernización del viejo aparato escolar — con «un estilo clasista opuesto a la aspiración, hoy generalizada, de democratizar la enseñanza», decía el preámbulo de la LGE-, con la consiguiente introducción de cambios profundos a nivel estructural para implantar un sistema que fuera capaz de responder a las exigencias de una sociedad con unas necesidades muy diferentes a las de décadas pasadas. Así las cosas, su objetivo principal se encaminó inicialmente a la formación de un equipo de profesionales competentes y eficientes capaces de detectar la verdadera situación del sistema educativo español para presentar, a partir de esas evidencias, una serie de propuestas de mejora. De este modo surgió en 1969 el denominado como "Libro Blanco» (La educación en España: bases de una política educativa) que supuso una crítica — documentada y rigurosaa la situación del sistema educativo, así como un planteamiento de las posibilidades de actuación futura. A partir de este documento, antesala y precedente inmediato a la LGE de 1970, se cimentaron ahora los más firmes pasos dados hasta el momento durante la época de la dictadura para articular una normativa que tuviera en cuenta que «los problemas educativos que tiene planteados hoy nuestro país requieren una reforma amplia, profunda, previsora, de las necesidades nuevas, y no medidas tangenciales y apresuradas con aspecto de remedio de urgencia» (Preámbulo de la Ley 14/1970, de 4 de agosto, General de Educación y Financiamiento de la Reforma Educativa, $B O E$, n. ${ }^{\circ} 187$, de 6 de agosto de 1970).

\footnotetext{
${ }^{20}$ Puelles Benítez, «Tecnocracia y política en la reforma educativa de 1970», 18.
} 


\section{LOS PRINCIPALES HITOS DE LA LGE DE 1970}

La LGE de 1970 tuvo como uno de sus principales puntales la implantación de un periodo formativo común de 8 años de duración, de los 6 a los 14 años (la denominada EGB —Educación General Básica-), con el que se pretendía desarmar el inaceptable sistema que condenaba a una mayoría a recibir una educación primaria pobre y desconectada de niveles superiores, mientras que una minoría se beneficiaba de una educación media y superior de carácter elitista. Romper con esta estructura bipolar que hacía de la enseñanza primaria un compartimento estanco, prácticamente ajeno al resto del sistema educativo y destinado a la clase popular, y ese otro compartimento de enseñanza media y superior, como niveles propios de la clase media y alta a los que sólo llegarían unos pocos, era el gran objetivo legislativo. Este nuevo sistema era considerado, dentro del texto legislativo, como el medio para acabar «con cualquier discriminación» y constituía "la base indispensable de igualdad de oportunidades educativas». Sin embargo, la aspiración por un nuevo procedimiento único y no discriminatorio (eliminación de pruebas selectivas y sustitución por un proceso de evaluación continua del rendimiento escolar) no tendría una sencilla implantación y, lamentablemente, sería pronto desvirtuado y falsificado por la práctica educativa. ${ }^{21}$

La LGE de 1970 abría su texto expositivo aludiendo precisamente a esa necesidad de "proporcionar oportunidades educativas a la totalidad de la población para dar así plena efectividad al derecho de toda persona humana a la educación» a la vez que debía atenderse «a la preparación especializada del gran número y diversidad de profesionales que requiere la sociedad moderna» (Preámbulo de la Ley 14/1970, de 4 de agosto, General de Educación y Financiamiento de la Reforma Educativa, BOE, n. ${ }^{\circ} 187$, de 6 de agosto de 1970). Así, la Ley, junto al intento por hacer efectiva la escolaridad obligatoria, aspiraba a resolver el déficit, algo más que centenario, de puestos escolares. ${ }^{22}$

En cuanto a la formación recibida durante el periodo de EGB, aparecía ésta ahora asociada a una terminología que trataba de dar muestra

\footnotetext{
${ }^{21}$ Puelles Benítez, «Tecnocracia y política en la reforma educativa de 1970», 25.

${ }^{22}$ Manuel de Puelles Benítez, «Evolución de la educación en España durante el franquismo», en Historia de la Educación. Edad Contemporánea, coords. Alejandro Tiana, Gabriela Ossenbach y Florentino Sanz (Madrid: UNED, 2002), 342.
} 
evidente del cambio de orientación en el modelo educativo. Se decía que estaba orientada a la adquisición, desarrollo y utilización funcional de los hábitos y de las técnicas instrumentales de aprendizaje, al ejercicio de las capacidades de imaginación, observación y reflexión, al desarrollo de aptitudes para la convivencia y para vigorizar el sentido de pertenencia a la comunidad local, nacional e internacional, a la iniciación en la apreciación y expresión estética y artística y al desarrollo del sentido cívico-social y de la capacidad físico-deportiva. Además, «los métodos didácticos habrán de fomentar la originalidad y creatividad de los escolares, así como el desarrollo de aptitudes y hábitos de cooperación, mediante el trabajo en equipo de Profesores y alumnos. Se utilizarán ampliamente las técnicas audiovisuales» (Preámbulo de la Ley 14/1970, de 4 de agosto, General de Educación y Financiamiento de la Reforma Educativa, BOE, n. ${ }^{\circ} 187$, de 6 de agosto de 1970).

Por lo que respecta a la enseñanza secundaria, la LGE de 1970 supuso no un cambio en el plan de estudios, sino todo un vuelco de la estructura general del sistema educativo. La prolongación de la EGB significó la extinción del bachillerato elemental —ahora denominado Bachillerato Unificado Polivalente (BUP)_, que pasó a ocupar tan solo tres cursos situados en las edades del antiguo Bachillerato Superior. Desapareció el curso preuniversitario sustituido por el Curso de Orientación Universitaria (COU). Todo este proceso de cambio iniciado en 1970 no culminó hasta 1979, con la consiguiente etapa transitoria a la enseñanza secundaria. Así pues, se produjo un intento por superar la dualidad del bachillerato -finalmente fallido tras el plan de estudios que se puso en marcha en 1975 y que dio al traste con este proyecto-, aspirando a que pudieran cumplirse los dos objetivos tradicionales asignados a este nivel: por un lado, preparar para los estudios superiores y, por otro, tener la suficiente entidad para facilitar la incorporación a la vida activa. Todo ello se intentó articular mediante la denominada polivalencia —entendiendo el bachillerato como sistema unificado que conducía a un título único y polivalente-, que se instrumentaba mediante la adecuada articulación de materias comunes, optativas y enseñanzas y actividades técnico-profesionales. ${ }^{23}$ Se proyectó la introducción de una metodología novedosa, considerando la acción docente

\footnotetext{
${ }^{23}$ Puelles Benítez, Política y educación en la España contemporánea, 115.
} 
en el bachillerato como una dirección del aprendizaje del alumno y no como una enseñanza centrada exclusivamente en la explicación de la materia, tendente a despertar y fomentar en el alumno la iniciativa, la originalidad y la aptitud creadora. A estos efectos, se recurría a técnicas de trabajo intelectual, tanto individual como en equipo, y los métodos de enseñanza deberían ser predominantemente activos - matizados de acuerdo con el sexo, apostillaba la Ley- y enfocados hacia una educación personalizada. La triste realidad es que aquel plan de 1975 resultó regresivo y presentó al final unas asignaturas teóricas carentes de conexión, escasas materias optativas, y una muy pobre propuesta para hacer frente a esa proyectada polivalencia, quedando así el intento de modernización claramente frustrado.

Para la formación profesional, frente a la anticuada concepción de la Ley de Formación Profesional Industrial de 1955, centrada en el aprendizaje de un oficio, la nueva Ley asumió una doble concepción de la misma: educativa y laboral. Desde el punto de vista laboral, sustituyó la concepción del oficio por la del logro de una profesión dentro de una familia de profesiones. Desde el punto de vista educativo, la formación profesional fue integrada en el nuevo sistema no como un nivel de enseñanza sino como la culminación laboral de un nivel educativo. ${ }^{24}$ La finalidad especificada en el texto legislativo para este nivel sería la de preparar al alumno en las técnicas específicas de la profesión por él elegida y en las cuestiones de orden social, económico, empresarias y sindical que comúnmente se presentan en ella. La realidad es que su aplicación quedó muy lejos de los objetivos propuestos.

En relación al ámbito universitario, las principales incorporaciones de esta nueva Ley fueron el acceso a la universidad para mayores de 25 años que no hubieran cursado el bachillerato, siempre y cuando se superaran las pruebas de acceso que a tales efectos propusieran los centros universitarios. Asimismo, se consagra la autonomía universitaria, siendo conscientes en todo momento que hablamos de un plano teórico o normativo, pero no real. Se señaló la necesidad de carreras de ciclo corto y, finalmente, se introdujo el sistema de organización departamental, como centro de la vida docente e investigadora.

\footnotetext{
${ }^{24}$ Puelles Benítez, «Tecnocracia y política en la reforma educativa de 1970», 27.
} 
Otra de las cuestiones a las que aspiraba la Ley era a la mejora del rendimiento y la calidad del sistema educativo. En este orden, se consideraba fundamental la formación y perfeccionamiento continuado del profesorado, así como la dignificación social y económica de la profesión docente. Sin embargo, lo cierto es que, durante la década de los setenta, se produjo una alta movilidad de profesorado, se dio una fuerte provisionalidad en los primeros años de carrera docente y se recurrió de forma masiva a la contratación de profesores interinos a causa de la rigidez del sistema de selección y la insuficiencia de plantilla en relación con la necesidad creciente de profesores, aspectos que, tal y como señala Antonio Viñao, «dificultaron todavía más la consecución de equipos docentes estables y cualificados». ${ }^{25}$

En cuanto a la terminología pedagógica de carácter modernizador se refiere, la LGE de 1970 introdujo la siguiente retahíla de conceptos cuya implantación y efectividad real cabría matizar en cada uno de los casos: centros experimentales, evaluación continua del rendimiento escolar, orientaciones pedagógicas, educación personalizada, Bachillerato internacional, curso de orientación universitaria, formación y perfeccionamiento del profesorado, programación educativa, acceso a la universidad para mayores de 25 años sin estudios, universidad a distancia, equipos docentes, seminarios didácticos, educación de adultos, fomento de la creatividad, áreas de enseñanza, enseñanzas de recuperación, materias optativas, servicios de orientación, departamento universitario, planificación de la educación, instituto universitario, tutoría, trabajo en equipo, técnicas de trabajo intelectual... ${ }^{26}$

\section{ICONOGRAFÍA DE LA MODERNIZACIÓN EDUCATIVA EN LOS INICIOS DE LA LGE A TRAVÉS DE LOS FONDOS DE LA AGENCIA EFE}

Para constatar en qué medida quiso transmitir el régimen franquista en su etapa final una imagen de modernización educativa a partir de la promulgación de la LGE hemos realizado, como se indicó en la in-

\footnotetext{
${ }^{25}$ Antonio Viñao Frago, «La educación general básica. Entre la realidad y el mito», Revista de Educación. La Ley General de Educación veinte años después, no. extraordinario (1992): 63.

${ }^{26}$ Agustín Escolano Benito, «Discurso ideológico, modernización técnica y pedagógica crítica durante el franquismo», Historia de la educación: Revista interuniversitaria 8 (1989): 15.
} 
troducción, un primer vaciado, inventario y catalogación de las fotografías digitalizadas de la fototeca de la Agencia EFE en el periodo 19701975 - posteriormente complementado con un muestreo por temáticas concretas en las décadas anteriores para constatar posibles cambios y continuidades en el discurso iconográfico generado a lo largo del franquismo- Con ello pretendemos realizar una primera aproximación y análisis de la iconografía sobre la reforma educativa impulsada en el contexto de la LGE de 1970 que el régimen franquista, mediante la Agencia EFE, quiso transmitir y propagar al exterior. Hay que tener en cuenta que dichas fotografías no tienen por qué ser las únicas de sus fondos, pues su proceso de digitalización continúa y los fondos digitalizados por épocas son susceptibles de ampliación. Del total de la muestra inicial del periodo analizado en profundidad, de 511 fotografías, que abarcan diferentes etapas de la educación formal, así como procesos educativos no formales (véase Tabla I anteriormente mencionada), se procedió a seleccionar aquellas que directamente guardaban relación con las etapas de escolarización contempladas en la LGE —educación infantil, primaria, secundaria y formación profesional-, manejando finalmente una muestra de 150 fotografías para el periodo 1970-1975. Dentro de este primer nivel de clasificación, hasta 85 de 150 fotografías corresponden a la etapa de Enseñanza General Básica (EGB), siendo importantes también las dedicadas a Preescolar, 29 de 150, y Formación Profesional (FP), 35 de 150, y prácticamente inexistentes las de la etapa de Bachillerato Unificado Polivalente (BUP) y el Curso de Orientación Universitaria (COU), tan sólo 1 de 150. Pasando a un segundo nivel de clasificación, dichas fotografías fueron catalogadas de acuerdo a su correspondencia con las categorías: de grupo, 8 de 150; de clase, 49 de 150; de espacios y edificios escolares, 8 de 150; de actividades ordinarias, 25 de 150; de actividades extraordinarias y/o festividades de la escuela, 23 de 150; y, finalmente, otras, 36 de 150 (véase Tabla II reproducida en la introducción). ${ }^{27}$

\footnotetext{
${ }^{27}$ Esta clasificación responde a las tipologías especificadas previamente en: Francisca Comas, Xavier Motilla y Bernat Sureda, «Escuela y fotografía, entre el testimonio y la construcción del discurso narrativo». Siguiendo dicha clasificación y adaptándonos a los fondos inventariados y catalogados de la Agencia EFE para este artículo, entendemos por fotografías de grupo aquellas que pretenden dar testimonio de quienes formaron parte de la institución educativa en un momento concreto, siendo generalmente la fotografía de un grupo escolar con su maestro o maestra de recuerdo de promoción. Por fotografía de clase nos referimos a aquellas que han sido tomadas en el interior de la clase y que responden a otra finalidad más allá del hecho de estrictamente dejar
} 
No obstante, debe tenerse en cuenta la dificultad existente, en muchas ocasiones, en la categorización de fotografías escolares de actividades ordinarias y extraordinarias, así como el hecho de que una misma fotografía sería susceptible de ser incluida en más de una categoría en función del aspecto en que se quiera incidir de ella. Es importante no perder de referencia que dicho conjunto de fotografías pertenecientes a la Agencia EFE fueron puestas a disposición de los medios de comunicación impresos para ilustrar las noticias educativas publicadas durante el periodo final del franquismo. Noticias, muchas de ellas, acontecidas como consecuencia de la gestación de la nueva legislación y de los cambios implementados con ella. Así pues, su interés y valor para nuestro trabajo radica en la posible utilización que el régimen habría hecho de ellas con fines propagandísticos, en mayor o menor medida, para proyectar una imagen pública de los principales hitos educativos que se alcanzaban en esos años en contraste con la etapa precedente o, por el contrario, en que muestran la pervivencia de tradiciones educativas pese a los cambios legislativos acontecidos. En definitiva, pretendemos dar respuesta a la cuestión que inicialmente nos planteamos ¿Qué imagen o discurso iconográfico educativo, consciente o inconscientemente, se promovió a través de la Agencia EFE con las fotografías tomadas para su posterior uso en los medios de comunicación? En este sentido, podemos avanzar, a partir de la amplia muestra de fotografías analizadas, una menor visualización iconográfica de modernización e innova-

constancia o testimonio de quienes eran los protagonistas de la fotografía. Son fotografías que nos pueden hablar de metodología, materiales, innovación o tradición, etc. reflejando la identidad que del centro se quería proyectar, siendo en muchas ocasiones instantáneas preparadas. Por fotografías de espacios y edificios escolares entendemos aquellas en qué su finalidad principal es fotografiar los espacios interiores o exteriores de los centros escolares o la edificación en su conjunto, fachada, etc., muchas veces con motivo de la inauguración de construcciones escolares, sin que en ellas aparezcan elementos humanos o sea su finalidad principal. Finalmente, por fotografías ordinarias y extraordinarias entendemos aquellas que, en el primer caso, dan cuenta de actividades escolares concretas que se desarrollan en el propio centro (exámenes, clases de gimnasia, laboratorios, actividad de aula, etc.) o, en el segundo caso, de actividades puntuales fuera del marco escolar relacionadas con salidas al exterior, festividades, espectáculos, etc. (excursiones, viajes de estudio, entregas de premios, carnavales, espectáculos teatrales, etc.). Asimismo, atendiendo a las particularidades concretas de los fondos de la Agencia EFE hemos dejado una última categoría miscelánea de fotografías que difícilmente se podían ubicar en las anteriores descritas por su finalidad al ser tomadas, aunque pueden aportarnos informaciones de espacios escolares; principalmente son fotografías publicadas con motivo del inicio de curso escolar en las que podemos ver a niños y niñas escolares de camino a los centros educativos, acompañados de adultos o solos, apareciendo o no los propios centros, pero no siendo en cualquier caso su finalidad principal proporcionar información sobre los edificios. 
ción metodológica educativa en la etapa de EGB, si bien se evidencia un interés en demostrar la extensión de la enseñanza obligatoria, y una mayor visibilidad iconográfica de modernización educativa en las etapas de Preescolar y FP, reflejándose la implementación de nuevas metodologías de enseñanza y la modernización de las instalaciones tanto en Preescolar como en FP.

Consecuentemente, entre las fotografías de clase de la etapa educativa infantil se pueden observar distribuciones del aula que favorecerían el contacto entre niños y niñas, el trabajo grupal, superando la tradicional distribución del espacio con los pupitres orientados hacia la mesa del profesor y la pizarra. Sin embargo, se observa una pervivencia del modelo de distribución tradicional del mobiliario en las fotografías correspondientes a la etapa de educación primaria o EGB localizadas y analizadas para el mismo periodo.

Debe tenerse en cuenta, tal como ha señalado Antonio Viñao, ${ }^{28}$ que unos años después de la promulgación de la LGE de 1970 se estableció un programa de necesidades - espacios, dimensiones, usos, etc.- para los colegios de EGB. Dicho programa, en cuanto a la organización pedagógica, implicaba además el abandono, como modelo único, de la estructura tradicional del aula con grupos homogéneos y enseñanza frontal, en favor de la diversificación en espacios flexibles para grupos no estáticos de diferentes dimensiones. Sin embargo, la realidad es que el aula, como compartimento cerrado para un grupo homogéneo de alumnos, siguió siendo, frente a otras posibilidades de agrupación, la realidad habitual - hecho que hemos podido constatar en la colección de fotografías que es aquí objeto de estudio-. En este terreno, como en el del currículo, la organización y la metodología, toda la innovación quedó en manos de algunos profesores usualmente aislados en centros diferentes - es decir, sin poder constituir equipos estables- e integrados en movimientos de renovación pedagógica. Innovación dificultada, asimismo, por la propia inercia del sistema, el bajo presupuesto de funcionamiento de los centros, la organización y la distribución del profesorado y el contexto autoritario en que debía llevarse a cabo. ${ }^{29}$

\footnotetext{
${ }^{28}$ Viñao Frago, «La educación general básica. Entre la realidad y el mito», 51.

${ }^{29}$ Viñao Frago, «La educación general básica. Entre la realidad y el mito», 61.
} 
Dos fotografías de aulas de Preescolar realizadas con motivo de la inauguración de nueve grupos escolares en distintos barrios de Madrid - con un total de 186 unidades y 7400 puestos escolares-, de una serie más amplia para ilustrar dicha noticia, son un claro ejemplo de ese intento de abandono de la estructura tradicional del aula. En ellas se constata la agrupación de mesas encaradas de dos a dos por grupos de cuatro, en un caso, o en forma hexagonal por grupos de seis, en otro. Los espacios son amplios, bien ventilados e iluminados y con mobiliario moderno. Dichas fotos, tomadas para ilustrar la inauguración de los nueve grupos escolares creados en Madrid en noviembre de 1970, con la visita del ministro de Educación y Ciencia José Luis Villar Palasí, reflejan un modo de trabajar en el aula, en concreto en educación preescolar, acorde a las orientaciones y recomendaciones que la nueva legislación educativa impulsada en los últimos años del franquismo pretendía implementar, a la vez que dan cuenta de unos edificios e instalaciones modernas (fotografía 1). Hay que tener en cuenta, no obstante, que en décadas precedentes a la promulgación de la LGE, durante la dictadura franquista, pueden encontrarse imágenes de la entonces llamada educación de párvulos, con distribuciones del alumnado parecidas, no siendo imputable exclusivamente a la nueva legislación un cambio metodológico profundo en dicha etapa. Así pues, si podemos observar un interés explícito por reflejar iconográficamente la modernización educativa con la creación de nuevos centros escolares y, por extensión, con voluntad expresa o no, de distribuciones en el aula que favorecerían la implementación de nuevas metodologías, sería mucho más acuciado y evidente dicho hecho a partir de los años setenta en los fondos consultados de la Agencia EFE. ${ }^{30}$

\footnotetext{
${ }^{30} \mathrm{Si}$ bien somos conscientes de que existen fotografías para dicho periodo de escolarización con distribuciones en el aula que favorecen el contacto entre los niños en décadas anteriores en otras colecciones, es destacable y significativa la importancia que desde el régimen se dio iconográficamente a dicho hecho a partir de la década de los años setenta en los reportajes fotográficos de la Agencia EFE. En décadas precedentes a la promulgación de la LGE, durante el periodo franquista, tan sólo se ha localizado una fotografía perteneciente a los fondos de la Agencia EFE digitalizados, en ese sentido, para la educación de párvulos en la que puede observarse una distribución del aula con los alumnos encarados y agrupados en grupos de cuatro o más niños en contraste con la mayor abundancia de ellas en el periodo que abarca los inicios de la nueva ley durante los últimos años de la dictadura. Se trata de una instantánea del fotógrafo Hermes Pato hecha en marzo de 1942 en la Escuela-Hogar del Colegio de la Sagrada Familia para los hijos de reclusos.
} 


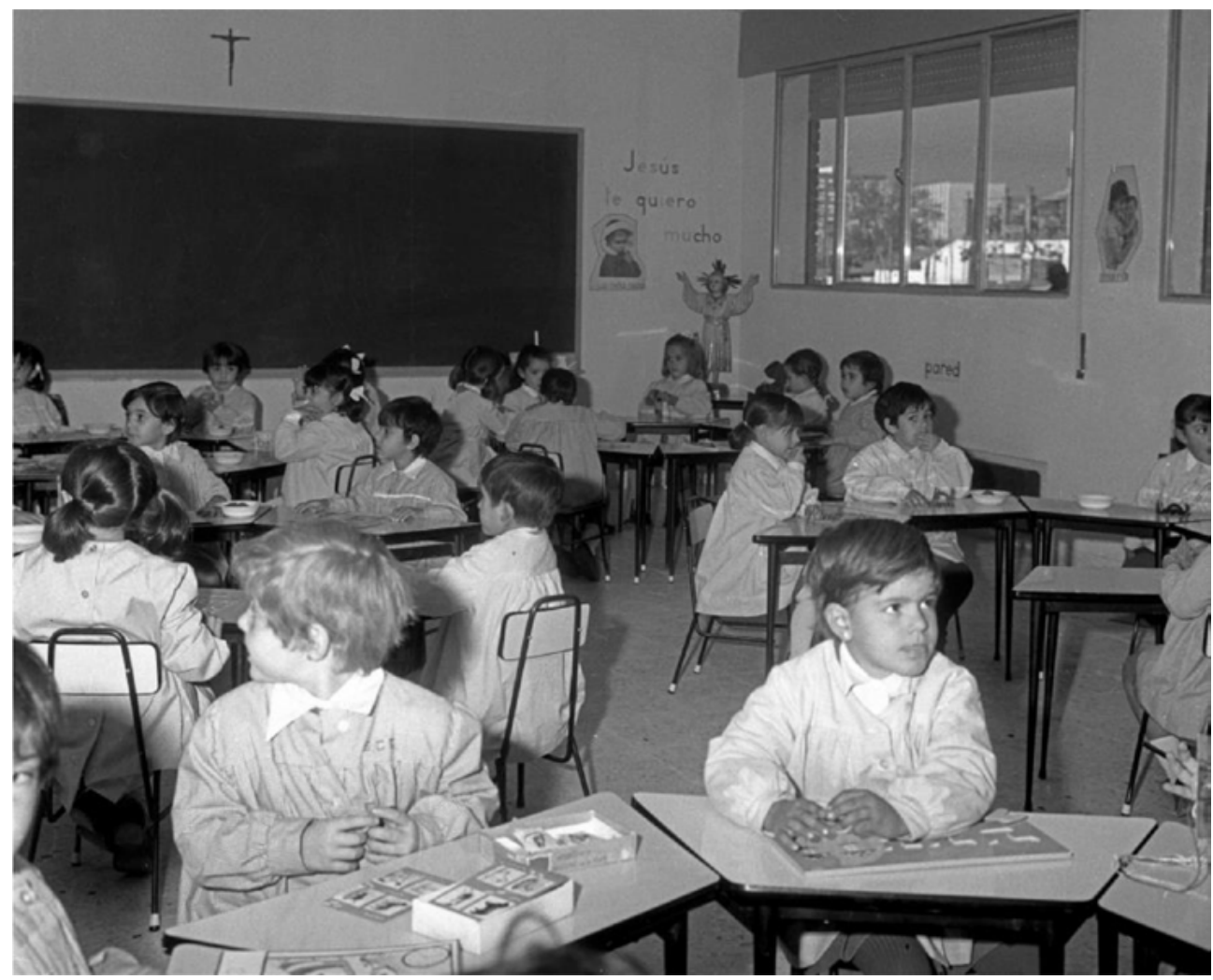

Fotografía 1. Aula de preescolar de uno de los nueve grupos escolares inaugurados en distintos barrios de Madrid, 3 de noviembre de 1970. Procedencia: EFE / lafototeca.com TAG ID: efespseven367948 - DocID: 3067454

Si contrastamos dichas imágenes con las de la misma tipología correspondientes a la etapa educativa de EGB, podremos observar cómo la distribución del mobiliario en el aula se rige por la tradicional orientación de mesas alineadas orientadas hacia el profesor y la pizarra. Una fotografía tomada con motivo de la visita de las autoridades del Ayuntamiento de Barcelona a las nuevas instalaciones de la Escuela del Bosque de Montjuich en octubre de 1972, que por entonces contaba con 560 plazas para alumnos de ambos sexos, constituye un claro ejemplo de lo que venimos diciendo (fotografía 2). En ella, desde la perspectiva del profesor o profesora, podemos ver un aula en la que los pupitres están distribuidos de dos en dos encarados hacia nuestra vista, con los alumnos levantados, ante la visita, a modo de saludo. Pese a que el mobiliario está renovado 
y permite su movilidad, la disposición se mantiene de acuerdo con los cánones tradicionales. El aula se intuye espaciosa, si bien no la vemos al completo, y llaman la atención los grandes ventanales que la iluminan de forma natural. La sensación es de una aglomeración de alumnos y alumnas superior a la que observamos en las anteriormente descritas para la educación de párvulos, intuyéndose unas ratios de alumnos por profesor elevadas. Otras dos fotografías de principios de junio de 1970, en la antesala de la aprobación de la nueva legislación educativa, correspondientes a colegios religiosos de Madrid, nos muestran unas aulas con mobiliario más antiguo y, en general, unas instalaciones menos modernas, pero con una distribución pareja del mobiliario del aula. En ambas, de la misma forma que en la foto anterior, la distribución de mesas está determinada por su orientación hacia el maestro o maestra. Una de ellas, tomada desde una perspectiva parecida a la anteriormente comentada de la Escuela del Bosque, contrasta por varios motivos con aquella: de entrada, el mobiliario, como se ha dicho, no es tan moderno; asimismo, observamos que es una escuela en la cual no se aplica la educación mixta y, si bien se intuye que los puntos de luz y ventilación natural deberían estar a nuestra derecha, la perspectiva de la fotografía no nos permite constatarlo, dando una sensación de menor luz natural en el aula. Como en la foto anteriormente comentada, la ratio de alumnas/profesora es también elevada. En la otra fotografía tomada en las mismas fechas, en meses previos a la promulgación de la LGE, en otro colegio religioso de Madrid - la Escuela de los Padres Salesianos de Atocha- observamos también unas instalaciones y mobiliario menos moderno que en las fotos de nuevos grupos escolares o de la Escuela del Bosque antes comentadas. La orientación de los alumnos y sus mesas es, como para las precedentes de la etapa educativa primaria, hacia el profesor y la pizarra. Sin embargo, en este caso, llama la atención la actitud de proximidad del docente hacia sus alumnos, así como la dinámica de clase en general con la participación de los discentes. Aspecto, este último, que contrasta claramente con la actitud del profesor y sus alumnos en la fotografía de febrero de 1970, capturada en una escuela del suburbio madrileño del Pozo del Tío Raimundo, en un aula en la que, como en las precedentes, el mobiliario está orientado hacia la figura del maestro, en este caso con una actitud de autoridad clara. Se constata, además, que no es un centro escolar de nueva construcción ni el mobiliario es moderno. 


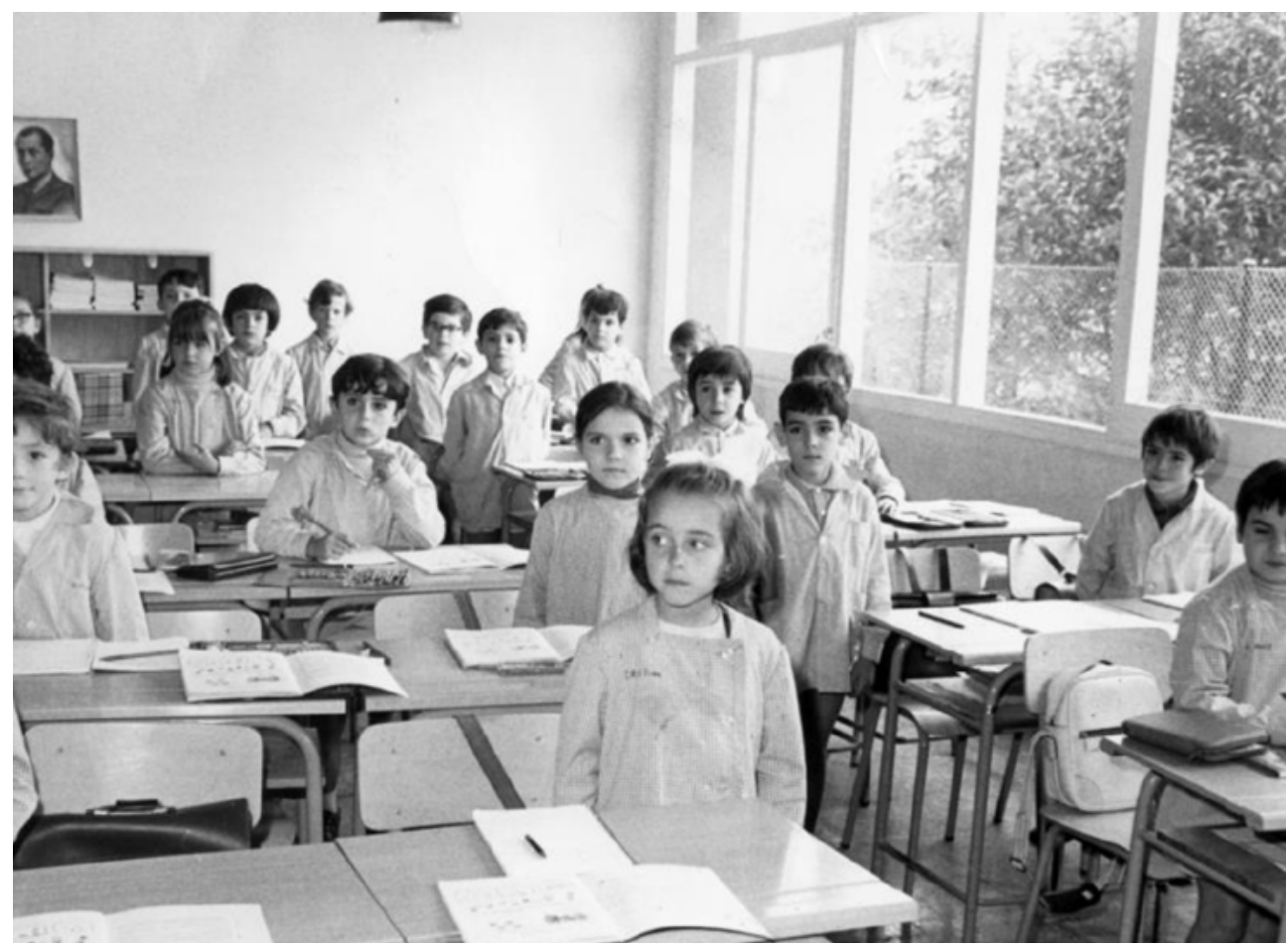

Fotografía 2. Aula de la Escuela del Bosque de Montjuich (Barcelona), 6 de octubre de 1972. Procedencia: EFE / lafototeca.com - TAG ID: efespseven375749 - DocID: 545816

Asimismo, de entre las diversas fotografías de actividad en el aula referentes a la FP podemos destacar dos de ellas que son reflejo de algunos cambios e innovaciones acaecidos en los prolegómenos de la promulgación de la LGE. En la primera de ellas, de febrero de 1970, perteneciente a un reportaje fotográfico sobre la Escuela de Decoración, podemos observar al profesor con las alumnas trabajando. El mobiliario está adecuado a la clase de dibujo y el profesor se pasea entre las alumnas atendiendo a una de ellas. Dicha fotografía, como la que comentaremos posteriormente, da cuenta del acceso de la mujer a la FP, si bien a una formación profesional específica que el régimen, la moral y sociedad conservadora del momento podían considerar adecuada y aceptable, en contraste con un momento en el que ya se habían producido importantes avances tras la aprobación de la Ley sobre derechos políticos, profesionales y de trabajo de la mujer de 22 de julio de 1961 y el posterior desbloqueo del no acceso de la mujer a actividades relacionadas con las armas y los cuerpos 
del Ejército, a la Administración de Justicia en los cargos de magistrados, jueces y fiscales y al personal titulado de la marina mercante en diciembre de 1966, avances en FP que la LGE pretendería consolidar ulteriormente. Aún así, es de interés la voluntad de reflejar dicho hecho, el acceso de la mujer a determinados estudios reglados de carácter profesionalizador y la adecuación de los espacios y mobiliario en que dicha formación se lleva a cabo, aun siendo una educación específica con un perfil socio-profesional de la mujer estereotipado. La siguiente fotografía que queremos destacar, de abril del mismo año, forma parte de una serie sobre la inauguración del Centro de Formación Profesional «San Vicente de Paúl», dependiente de la Cámara de Industria de Madrid. En ella, como en la anterior, constatamos el acceso de la mujer a la formación profesional: en este caso nos aproxima al interior de un aula de corte y confección. En ambos casos, el mobiliario está específicamente adaptado a las necesidades de los estudios: en el primero de ellos con mesas inclinadas diseñadas para el dibujo; en el segundo con máquinas de coser.

Diversas fotografías sobre un curso de Promoción Profesional del Servicio de Empleo y Ayuda de la Formación en un centro de FP de Paracuellos de Jarama, realizadas en octubre de 1975, nos aproximan a aulas específicamente diseñadas según su funcionalidad, clases de dibujo, mecánica, etc. Dicha serie de fotografías refleja la modernización de las instalaciones de este centro. El mobiliario del aula de dibujo, en la que los alumnos están realizando una prueba, consta de retroproyector, pizarra amplia, mesas inclinadas, amplios ventanales, etc. Asimismo, el aula de mecánica, donde los alumnos están también realizando una prueba o clase práctica, tiene diferentes herramientas con las que los estudiantes trabajan individualmente bajo la supervisión del profesor (fotografía 3). Ambos espacios son amplios y están dotados de materiales y mobiliario adecuado a sus fines. Dichas fotografías son un reflejo de la actividad ordinaria en el centro educativo profesional en cuestión, pues constituyen instantáneas tomadas en el transcurso de sendas pruebas específicas realizadas por los alumnos, si bien su categorización como actividad ordinaria no es obstáculo para que puedan ser consideradas a su vez, si no tuviéramos más información sobre ellas, como fotografías de clase, o para que nos den información sobre los espacios interiores del centro educativo. Otra fotografía susceptible de ser considerada de actividad ordinaria, de la Escuela de Náutica de Alicante, tomada en febrero de 1971, 
nos da una imagen diferente al ver a los alumnos fuera del centro en una clase práctica en el puerto alicantino donde un pescador veterano les está enseñando a realizar nudos marineros. Dicha fotografía es interesante por reflejar actividades prácticas más allá del propio centro formativo, aprovechando las enseñanzas de profesionales del sector; en definitiva, de una formación profesionalizadora que tiene en cuenta y aprovecha los espacios y profesionales ajenos a la propia institución educativa.

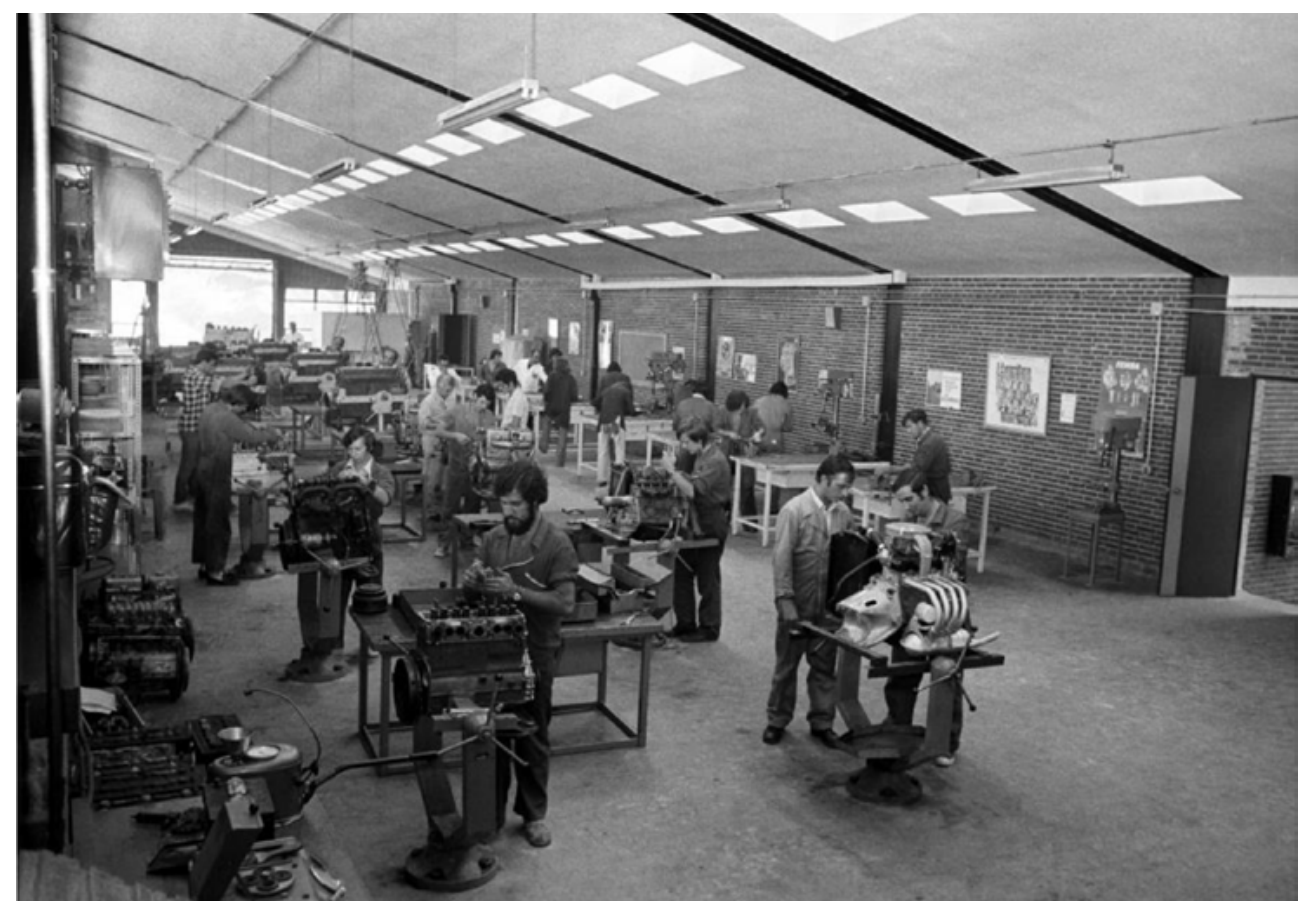

Fotografía 3. Alumnos realizando un ejercicio de mecánica durante un curso de Promoción Profesional del Servicio de Empleo y Ayuda a la Formación en Paracuellos de Jarama (Madrid), 16 de octubre de 1975. Procedencia: EFE / lafototeca.com - TAG ID: efespsix329718 Código de Referencia: 48409465

Las fotografías de actividad ordinaria y extraordinaria de educación preescolar, catalogadas e inventariadas para el periodo analizado, nos aproximan principalmente a juegos de los alumnos en el patio, en el caso de las primeras, y de actividades extracurriculares con motivo de alguna visita al centro educativo, en el de las segundas. Son ejemplos de las primeras, diversas fotografías entre las que se puede destacar una del inicio del 
curso escolar de 1970-1971 en un colegio público de Madrid. En ella vemos a los niños y niñas formando un círculo o corro y cantando con su maestra (fotografía 4). El juego del corro ha sido interpretado como símbolo del grupo y sería susceptible de constituir una señal con efectos propagandísticos. A su vez, el patio se erige en lugar que sirve al fotógrafo para la representación de juegos espontáneos. Los niños y niñas llevan uniforme escolar y la actitud y el gesto corporal es distendido y lúdico. Este tipo de fotografías no son usuales para la etapa de escolarización posterior, la EGB, si bien podemos encontrar algunos ejemplos como una fotografía de septiembre de 1970, realizada con motivo del inicio de curso, de la misma serie que la anteriormente comentada, en que se ve a un grupo de niñas jugando al corro en el patio, vestidas con el uniforme. Una fotografía de mayo de 1972, de alumnos de un colegio de EGB realizando ejercicios de educación física en la playa del El Postiguet de Alicante, es un reflejo del aprovechamiento de los espacios naturales próximos al colegio para la realización de actividades ordinarias, en este caso ejercicios de gimnasia en el transcurso de la clase de educación física (fotografía 5).

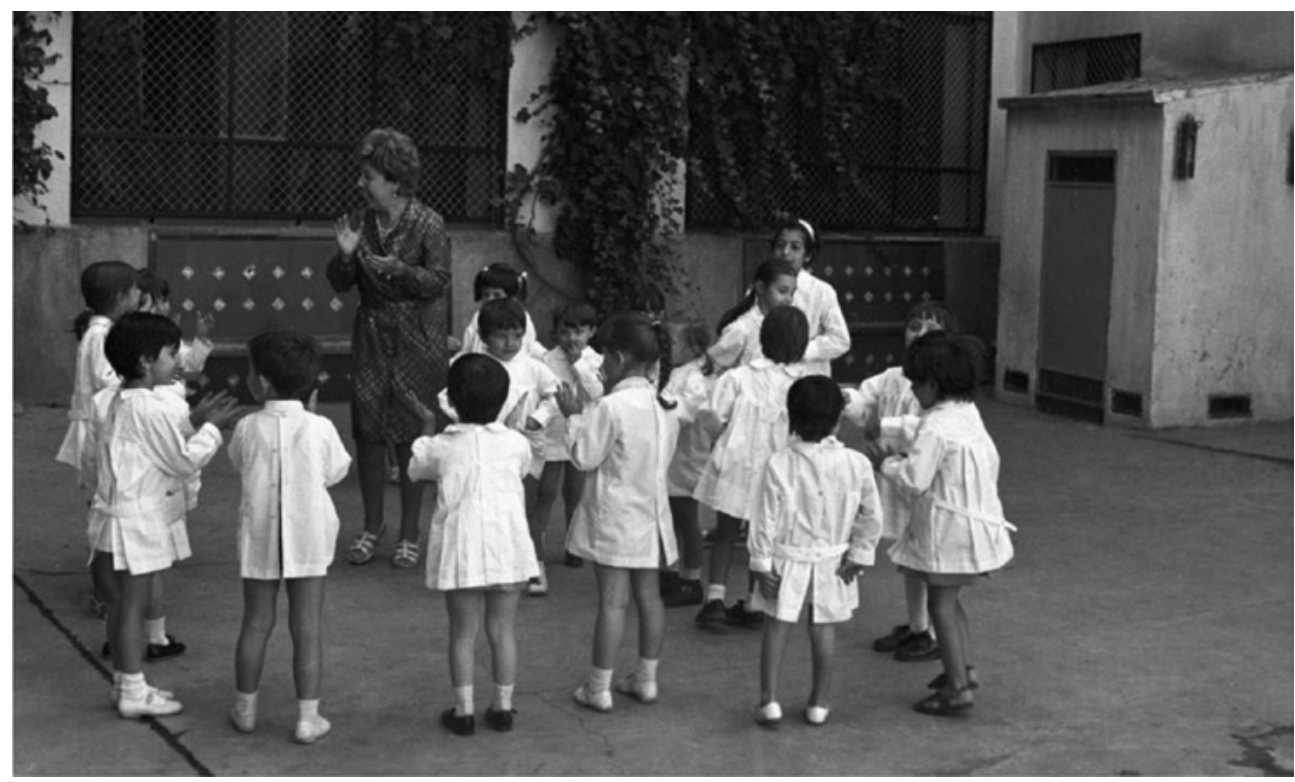

Fotografía 4. Alumnos de párvulos de un colegio público de Madrid jugando y cantado en el patio con su profesora, 25 de septiembre de 1970. Procedencia: EFE / lafototeca.com TAG ID: efespseven367804 - DocID: 3068784 


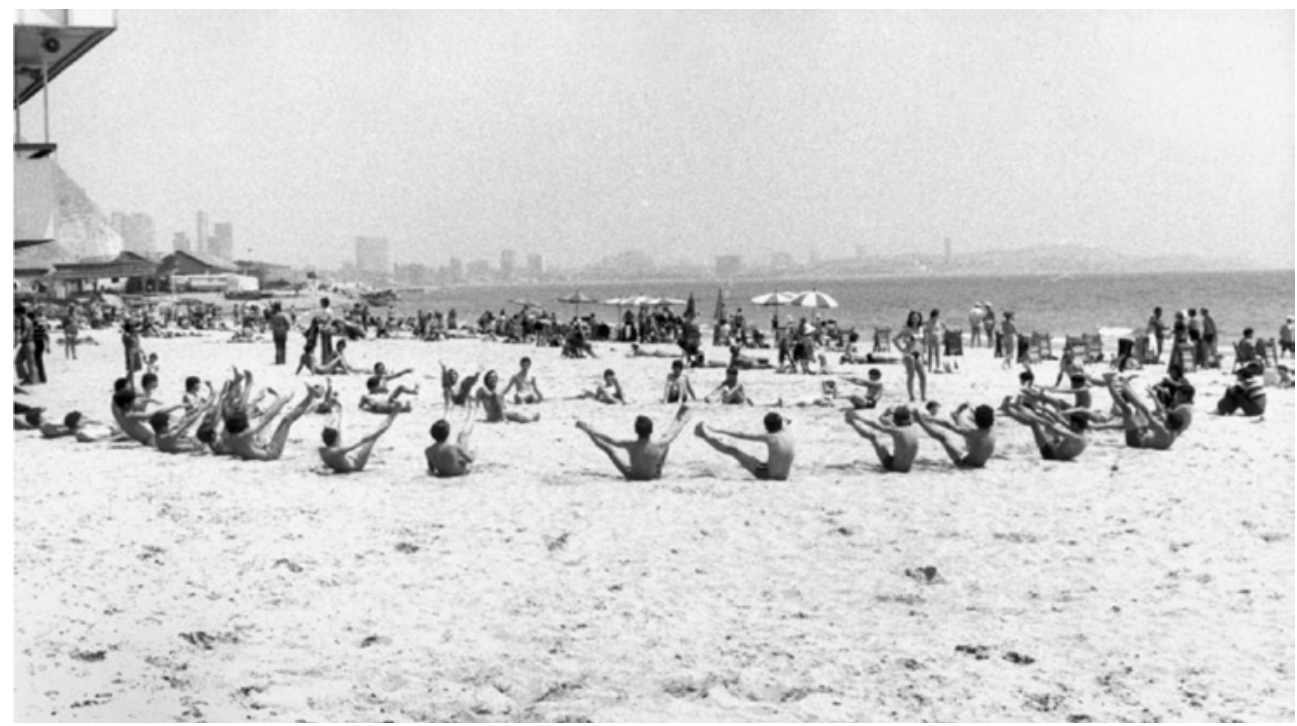

Fotografía 5. Alumnos de un colegio realizando una clase de gimnasia en la playa de El Postiguet (Alicante), 17 de mayo de 1972. Procedencia: EFE / lafototeca.com TAG ID: efespseven376046 - DocID: 613074

En contraste con el fenómeno de sistemática supresión de escuelas rurales que acontece a finales del franquismo, al tiempo que se construían colegios comarcales con servicios de transporte y comedor - política seguida y prolongada en los años setenta para posibilitar una emulación del modelo colegial, a imagen y semejanza de los institutos de secundaria—, ${ }^{31}$ hubo interés por parte del régimen de propagar iconográficamente, a través de fotografías para la etapa de EGB de actividad ordinaria, la extensión de la escolarización a zonas despobladas o barrios marginales. Así, en una serie de ellas vemos a los alumnos de la por entonces considerada escuela más pequeña de España, ${ }^{32}$ de un barrio marginal de Alicante, San Agustín, esperando para entrar a las instalaciones ubicadas en una cueva, en una de ellas, y saludando a su nuevo maestro, en otra. Dichas fotografías dan cuenta de la extensión de la enseñanza a zonas marginales, en la década de

\footnotetext{
${ }^{31}$ La LGE lo señala como meta históricamente buscada: que los centros de EGB tuvieran, al menos, una unidad por cada uno de los cursos (Art. 59). Vid. Julio Mateos, «La marcha hacia la educación tecnocrática y de masas: sociedad y educación en España (1939-1970)».

${ }^{32} \mathrm{Si}$ atendemos a la información descriptiva que sobre dicho conjunto de fotografías consta en el catálogo de la fototeca de la Agencia EFE.
} 
los setenta, y a sectores de la población tradicionalmente alejados de la escolarización, en este caso concreto familias de etnia gitana de dicha barriada. De igual modo, otra fotografía, de mayo de 1973, perteneciente a una serie de Volkhart Müeller, sobre el colegio de Las Hurdes (Cáceres), recoge una imagen de los niños en el comedor. En este caso, se trata de un Centro de Concentración Escolar, locales escuelas o edificios escolares que albergan a alumnos y maestros, concretamente para la fotografía en cuestión en una de las comarcas más deprimidas de España. Como en la serie de fotografías anteriormente comentada, vemos un interés por ofrecer una imagen y proyección pública de la preocupación del régimen por hacer llegar la escolarización obligatoria a las zonas más deprimidas y marginales del país.

Entre las fotografías de actividades extraordinarias para las distintas etapas de escolarización son frecuentes las que dan cuenta de espectáculos

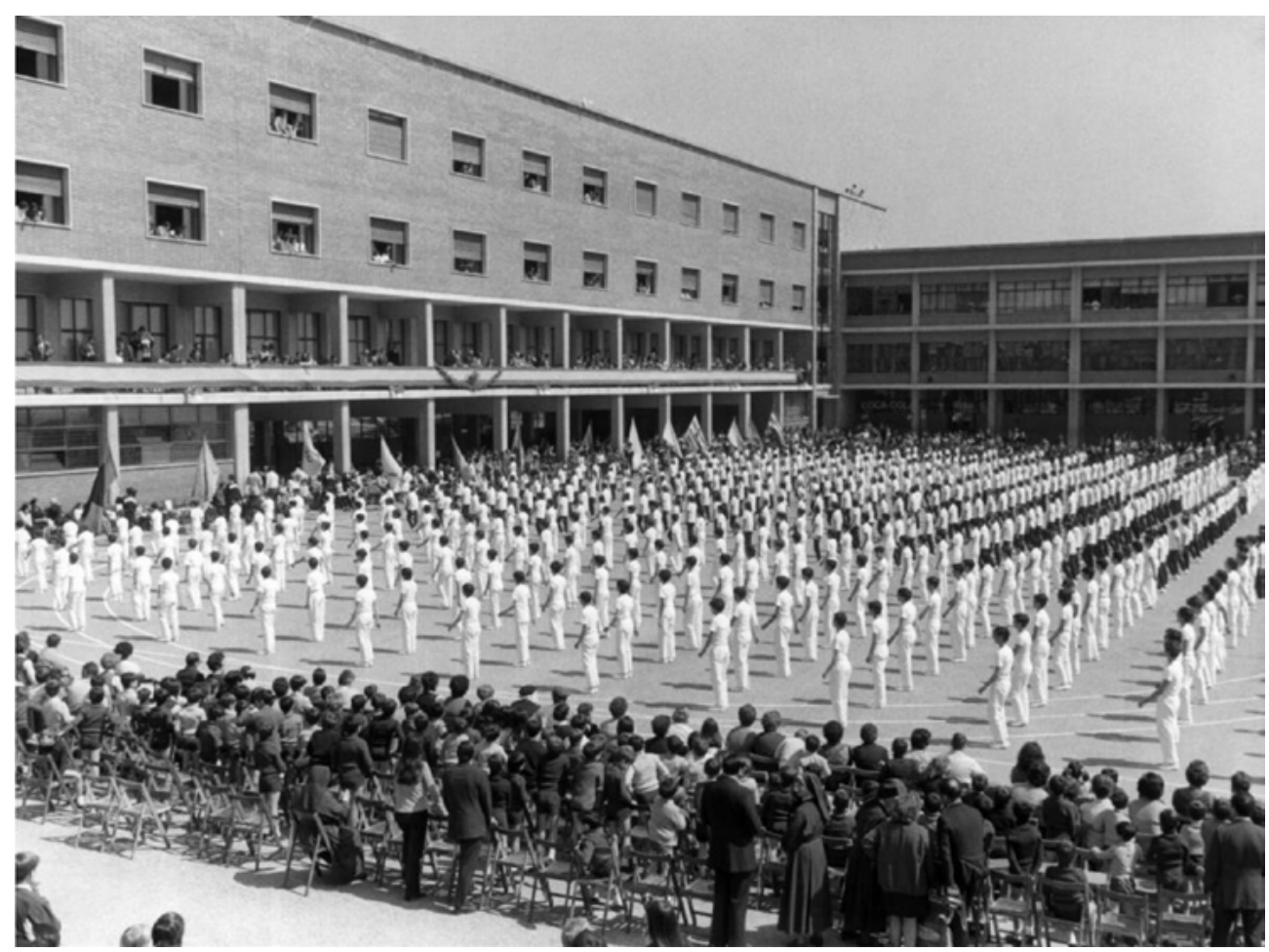

Fotografía 6. Festival gimnástico en los «Hogares Ana Gironella de Mundet» de la Diputación de Barcelona y la familia Mundet, 17 de abril de 1972. Procedencia: EFE / lafototeca.com TAG ID: efespseven377157 - DocID: 3957279 
gimnásticos en momentos puntuales y con ocasión de actos excepcionales. Son ejemplo de ello diversas fotografías de abril de 1972 del festival gimnástico de los niños y niñas de los Hogares «Ana Gironella de Mundet» de la Diputación de Barcelona y la familia Mundet (fotografía 6). Otras documentan visitas de autoridades con motivo de la inauguración de nuevas instalaciones o de los actos de clausura de los cursos, con entregas de diplomas; por ejemplo, una fotografía de junio de 1972, que forma parte de una serie más amplia sobre la Escuela de Especialidades «Julio Ruiz de Alda», en que el secretario general del Movimiento, Torcuato Fernández Miranda, junto a la delegada nacional de la Sección Femenina, Pilar Primo de Rivera, y otras personalidades del régimen presiden la entrega de diplomas a las alumnas.

Aunque no sean mayoritarias, con motivo de la construcción e inauguración de nuevos centros escolares en los años previos a la promulgación de la nueva legislación y durante los años finales del franquismo, también podemos encontrar fotografías que muestran instalaciones sin actividad escolar en ellas, tan sólo arquitectónicamente; es decir, de aquello que hemos catalogado como fotografías de espacios y edificios escolares. La arquitectura escolar sirve aquí como reclamo para representar la modernización tanto de la escuela como de los centros educativos de FP. Generalmente son fotografías tomadas con motivo de la finalización de la construcción o de la inauguración de un nuevo centro escolar, público o privado. En este caso, esa intención propagandística que busca proyectar visualmente el incremento y la renovación de los edificios escolares, se utiliza a pesar de que conocemos perfectamente las carencias que durante este periodo se producían como consecuencia de la falta de inversión económica en cantidad adecuada para hacer frente al progresivo incremento de matrícula. Podemos encontrar ejemplos de ellas para los distintos periodos de escolarización obligatorios y postobligatorios. Así, para las etapas de Preescolar y EGB podemos destacar la fotografía de la fachada y espacios exteriores del Colegio "Cuestablanca» en Madrid, de principios de los setenta, obra del arquitecto Miguel Fisac Serna, u otra fotografía de noviembre de 1970 perteneciente a una serie más amplia, ya comentada, con motivo de la inauguración de nueve centros escolares en Madrid en diferentes zonas. También pueden comentarse fotografías de edificios de nueva construcción para las etapas postobligatorias, como la tomada de la nueva fa- 
chada del Instituto o Liceo Francés de Madrid, de mayo de 1971, o una del moderno edificio del Instituto Politécnico de Valencia, de junio de 1970, en la antesala de la aprobación de la LGE, perteneciente a una serie más amplia de dicho centro con motivo de su inauguración y consiguiente visita de autoridades. Esta tipología de fotografías, además de testimoniar la creación de nuevos centros escolares y de sus modernas instalaciones, en su mayoría construidos a instancias del régimen, son un testimonio de la importancia que se quiso dar públicamente al impulso de las construcciones escolares, iniciado previamente a la promulgación de la LGE, pero que dicha ley pretendería consolidar, para generalizar la enseñanza obligatoria, aumentando el parque escolar y modernizando y ampliando las instalaciones relacionadas con la oferta formativa profesional en los años finales del franquismo.

Curiosamente, frente a las marchas forzadas con las que empezaron a construirse en los años sesenta ampliaciones de los Institutos oficiales de bachillerato por toda España, con las llamadas secciones filiales o delegadas, y aprovechando los edificios con estudios nocturnos y otras medidas de urgencia, hay una ausencia prácticamente total de fotografías sobre Institutos y el bachillerato en los fondos analizados, ${ }^{33}$ no así para la FP, tal y como hemos visto.

Finalmente, un numeroso grupo de fotografías generadas con motivo del inicio de curso escolar, capturadas para ilustrar dichas noticias curso a curso, y de difícil catalogación por sus finalidades intrínsecas, nos muestran a escolares, en ocasiones acompañados de adultos o solos en otras, de camino al colegio. En algunas de estas fotografías podemos ver el centro escolar parcialmente, si bien la finalidad en la toma no era esa. En otras, el recurso del fotógrafo en el encuadre prioriza al niño o niña, generalmente de espaldas con elementos escolares en su posesión que nos indican que se dirige al colegio. Son fotografías que por sí mismas serían susceptibles de ser consideradas en una categoría específica independiente de las hasta aquí comentadas, reflejo del anonimato de miles de escolares en su vuelta al colegio después de las vacaciones estivales, que reflejan el interés e importancia que desde la Agencia EFE se otorgaba a dicho hecho para ser difundido en los medios escritos.

\footnotetext{
${ }^{33}$ La única localizada pertenece al Instituto o Liceo Francés de Madrid, data de mayo de 1971, y es capturada con motivo de la construcción de su nuevo edificio.
} 


\section{CONCLUSIONES}

La LGE de 1970 supuso un intento de modernización del sistema educativo español, inserto en un proyecto renovador del aparato productivo y del cuerpo social mucho más amplio y, en buena medida, favorecido por la situación internacional. Sin embargo, tanto la penosa situación del aparato escolar y la insuficiente inversión económica como, sobre todo, el mantenimiento del régimen dictatorial, generaron rápidamente ciertas incoherencias entre el nuevo marco normativo y la realidad educativa del momento y de años venideros. Esta combinación sinérgica entre modernidad y tradición se ve claramente plasmada en el discurso visual de la colección de fotografías de la Agencia EFE que ha sido analizada en este trabajo. El régimen, haciendo uso propagandístico de esta agencia periodística, habría pretendido proyectar una imagen de modernidad, especialmente visible en los niveles de la entonces llamada educación preescolar y de la FP; pero al mismo tiempo, otras tantas fotografías se convertirían, para el espectador actual, en evidentes muestras de pervivencias e inercias de ese modelo tradicional. Coincide todo ello con lo que apuntaba hace tiempo Puelles Benítez al afirmar que la LGE de 1970 representa un texto de carácter híbrido, es decir, aúna aspectos antiguos y modernos. El tradicionalismo habría quedado plasmado mediante la inclusión de "principios impuestos por la línea política del régimen», y la línea modernizadora se haría patente porque «enlaza con los principios innovadores que inspiraron las reformas educativas en la Europa de los años sesenta». ${ }^{34}$ En la raíz de esta cuestión se encuentra la concepción de la educación como un asunto más técnico que político, de la que se derivaría esa ambigüedad de la Ley en ciertos aspectos.

La colección de fotografías de la Agencia EFE analizadas, utilizadas por el régimen con finalidad propagandística para difundirlas principalmente en medios escritos, nacionales y extranjeros, sobre la situación educativa en España a finales del franquismo - coincidiendo con la gestación, promulgación y primeros años de implementación de la LGEevidencia, principalmente, aspectos tales como: la extensión de la enseñanza obligatoria, con el consiguiente aumento de centros educativos - en este caso se hace un uso de la arquitectura escolar y del aumento de construcciones escolares como elementos para proyectar una imagen

\footnotetext{
${ }^{34}$ Puelles Benítez, Politica y educación en la España contemporánea, 113.
} 
renovadora-; la modernización de la FP —estudios, espacios, recursos, etc.- y el acceso de la mujer a la misma. Estas cuestiones no tendrían por qué ir asociadas necesariamente a un cambio metodológico real de la educación. De hecho, tal y como hemos podido constatar en las fotografías analizadas, se observa como en periodos escolares de educación preescolar y EGB se contraponen modelos de distribución del mobiliario que en un caso favorecerían la innovación metodológica en el aula, facilitando las dinámicas grupales, espacios de trabajo compartido y la educación personalizada, y en otro se mantendría una concepción más tradicional ligada a la clase magistral. Aun así, frente a esta última concepción que se visualiza principalmente a través de las fotografías de aula, podemos, en contraste, atisbar signos de una intencionalidad de propagar una imagen educativa modernizada en instantáneas que reflejan actividades desarrolladas fuera de los muros escolares.

Sin duda, algunas de las medidas adoptadas durante la década de los sesenta y la posterior promulgación de la LGE de 1970 abrieron el camino hacia la modernización. A pesar de detectar contradicciones y discordancias en las fotografías, se aprecia una intencionalidad manifiesta por proyectar una imagen de cambio y progreso, en evidente sintonía con la concepción global de la reforma que se emprende con la promulgación de esta Ley que mostraría una clara tendencia hacia el cambio y una pretensión de introducción de diversas novedades con carácter modernizador.

Todo el proceso de reforma emprendido, previa y posteriormente a la promulgación de la LGE de 1970, habría tenido una clara dimensión propagandística, que también se habría visto reflejada en la imagen que se proyectó de ella en la prensa escrita a través de las fotografías distribuidas por la Agencia EFE. Tal y como habría señalado Aranguren, se trataba

de seguir unas modas y de montar unas ficciones. «Planeamiento» $\mathrm{y}$ «Programación» hacen moderno y parecen una superación del individualismo sin dejar de sonar completamente a «occidental» [...]. Se trata de Política o Propaganda a propósito de la educación. ${ }^{35}$

\footnotetext{
${ }^{35}$ José Luis López Aranguren et. al., Planificación educativa (Barcelona: Nova Terra, 1975), 23-24.
} 
Con todo, ni la aprobación del texto legislativo, de inspiración tecnicista, y su implementación, ni la imagen que el régimen habría querido propagar del proceso modernizador educativo de esos años, habrían incoado el cambio sin la complicidad de la transformación general de mentalidad de la sociedad española y, sobre todo, del trabajo de un profesorado que fue el encargado real de hacer cambiar el panorama de las aulas en el país.

\section{Nota sobre los autores}

Xavier Motilla Salas es doctor en Ciencias de la Educación. Profesor contratado doctor del Departamento de Pedagogía y Didácticas específicas de la Universitat de les Illes Balears (UIB). Es miembro del Grupo de Estudios de Historia de la Educación (IRIE/UIB) desde su creación. Es secretario de redacción de la revista Educació i Història, miembro de comités científicos de diversas revistas científicas histórico-educativas y vocal de la Societat d'Història de l'Educació - IEC y de la Sociedad Española de Historia de la Educación (SEDHE). Ha centrado su labor investigadora en la historia de la educación contemporánea, con temáticas relacionadas con la sociabilidad, el asociacionismo y la educación fuera de la escuela, la renovación educativa y, en los últimos años, la fotografía y la historia de la educación.

SARa González Gómez es doctora en Ciencias de la Educación por la Universidad de Salamanca (USAL) y profesora ayudante doctor del Departamento de Pedagogía y Didácticas específicas de la Universitat de les Illes Balears (UIB). Es miembro del Grupo de Estudios de Historia de la Educación (IRIE/UIB) y del grupo de investigación reconocido Memoria y proyecto de la educación (USAL). Es coeditora de las revistas Espacio, Tiempo y Educación y Foro de Educación y pertenece al equipo editorial de Educació i Història. En cuanto a líneas de investigación, ha cultivado especialmente la historia de las universidades, de la fotografía como fuente en historia de la educación, de la prensa pedagógica y de la opinión pública en educación a través de la prensa. 


\section{REFERENCIAS}

Aguiló, Catalina, Maria J. Mulet and Paula PinYa. «La fotografia de temàtica escolar en arxius no especialitzats. Notes sobre fons en imatge a Mallorca». Educació i Història. Revista d'història de l'educació 15 (2010): 73-98.

ARGERICH, Isabel. «Imatges fotogràfiques de temàtica educativa en col-leccions i arxius públics i privats». Educació i Història. Revista d'història de l'educació 15 (2010): 55-72.

BASSARGETTE, Élisabeth. «Le mouchoir illustré rouennais. Une imagerie éducative». Historie de l'Education 30 (1986): 61-66.

Benjamin, Walter. Discursos interrumpidos I. Buenos Aires: Taurus, 1989.

BRASTER, Sjaak. «How (un-)useful are for understanding histories of education? About teacher centeredness and new education in Dutch primary schools: 1920-1985». Educació i Història. Revista d'història de l'educació 15 (2010): 123-148.

Burke, Catherine. "Hands on history: Towards a critique of the "everyday" ». History of Education. Journal of the History of Education Society 30, no. 2 (2001): 191-201.

- "The body of the schoolchild in the history of education». History of Education. Journal of the History of Education Society 36, no. 2 (2007): 165-171.

Burke, Catherine y Ian Grosvenor. "The progressive image in the history of education: stories of two schools». Visual Studies 22, no. 2 (2007): 155-168.

Burke, Catherine y Helena Ribeiro de CAstro. «The school photograph: Portraiture and the art of assembling the body of the schoolchild». History of Education. Journal of the History of Education Society 36, no. 2 (2007): 213-226.

Chassagne, Serge. "Éducation et peinture au XIX ${ }^{\mathrm{e}}$ siècle: un champ iconique en friches». Historie de l'Education 30 (1986): 53-59.

Comas, Francesca. «Presentació: Fotografia i Història de l’Educació». Educació $i$ Història. Revista d'història de l'educació 15 (2010): 9-15.

Comas, Francesca, Sara González, Xavier Motilla y Bernat Sureda (eds.). Imatges de l'escola, imatge de l'educació. Palma: Universitat de les Illes Balears, 2014.

Comas, Francesca, Miquel MARCH y Bernat SuredA. «Les pràctiques educatives de l'escoltisme de Mallorca durant la dictadura franquista a través de les fotografies». Educació i Història. Revista d'història de l'educació 15 (2010): 195-126.

Comas, Francesca, Xavier Motilla y Bernat Sureda. Fotografia i història de l'educació. Iconografia de la modernització educativa. Palma: Lleonard Muntaner Editor, 2012.

- «Escuela y fotografía, entre el testimonio y la construcción del discurso narrativo». En Patrimonio y Etnografía de la escuela en España y Portugal durante el siglo XX. III Foro Ibérico de Museísmo Pedagógico. V Jornadas Científicas 
de la Sociedad Española para el Estudio del Patrimonio Histórico Educativo (SEPHE), editado por Pedro Moreno y Ana Sebastián, 405-417. Murcia: Universidad de Murcia, CEME, SEPHE, 2012.

- «Iconografía y representación gráfica de las colonias escolares de la Diputación de Baleares. Una aproximación a través del análisis de las fotografías de las memorias». Revista Española de Pedagogía, año LXix 269 (2011): 445-462.

Comas, Francesca y Bernat SuREDA. «Photography and advertising of the Maria Montessori method in Spain (1911-1931)». Paedagogica Historica 48, no. 4 (2012): 571-578.

- «Proposals for women's education in the magazine Feminal». History of Education \& Children Literature VIII, no. 2 (2013): 273-292.

Delgado IdarReta, José Miguel. "Prensa y propaganda bajo el franquismo». En Centros y periferias: prensa, impresos y territorios en el mundo hispánico contemporáneo: homenaje a Jacqueline Covo-Maurice, editado por Nathalie Ludec and Françoise Dubosquet Lairys, 219-231. Paris: PILAR, 2004.

Depaepe, Marc y Bregt Henkens (eds.). Imagine, all the education... The visual in the making of the educational space through history. Programme and abstract book of the XXth International Standing Conference for the History of Education. Leuven: ISCHE, 1998.

- «The History of Education and the Challenge of the Visual». Paedagogica Historica. International journal of the history of education 36, no. 1 (2000): 11-17.

DepaePE, Marc y Frank Simon. «Sobre el treball amb fonts: consideracions des del taller sobre història de l'educació». Educació i Història. Revista d'història de l'educació 15 (2010): 99-122.

Díaz, Elías. De la Institución a la Constitución. Política y cultura en la España del siglo Xx. Madrid: Trotta, 2009.

Escolano Benito, Agustín. «Discurso ideológico, modernización técnica y pedagógica crítica durante el franquismo». Historia de la educación: Revista interuniversitaria 8 (1989): 7-28.

GauluPeu, Yves. «L'historie en images à l'école primaire. Un exemple: la Révolution française dans les manuels élémentaires (1870-1970)». Historie de l'Education 30 (1986): 29-52.

GeLABERT, Llorenç and Xavier Motilla. «Imatge, formació religiosa i educació a la revista il.lustrada Lluc (1921-1973)». Educació i Història. Revista d'història de l'educació 24 (2014): 103-134.

GIL VILLA, Fernando. «El estudiante como actor racional. Objeciones a la teoría del capital humano». Revista de Educación 306 (1995): 315-327.

Grosvenor, Ian. "From the "Eye of History" to "a Second Gaze": The visual archive and the marginalized in the history of education». History of Education. Journal of the History of Education Society 36, no. 4 (2007): 607-622. 
— «The school album: images, insights and inequalities». Educació i Història. Revista d'història de l'educació 15 (2010): 149-164.

Grosvenor, Ian y Martin Lawn. "Ways of seeing in education and schooling: emerging historiographies». History of Education. Journal of the History of Education Society 30, no. 2 (2001): 105-108.

Grosvenor, Ian, Martin Lawn y Kate Rousmaniere (eds.). Silences and images. The social history of the classroom. Nova York: Peter Lang, 1999.

Hernández-Navarro, Miguel A. Materializar el pasado: el artista como historiador (benjaminiano). Murcia: Micromegas, 2012.

Jiménez Trujillo, José F. «Another View on Education: Educational Policy of the Second Republic of Spain Seen from Pictorial Humor in Satirical and Conservative Press». Paedagogica Historica. International journal of the history of education 36, no. 1 (2000): 427-448.

LAWn, Martin y Ian Grosvenor. "When in doubt, preserve”: exploring the traces of teaching and material culture in English schools». History of Education. Journal of the History of Education Society 30, no. 2 (2001): 117-127.

López Aranguren, José Luis et. al., Planificación educativa. Barcelona: Nova Terra, 1975.

MARGOLIS, Eric y Sheila FrAM. «Caught napping: Images of surveillance, discipline and punishment on the body of the school child». History of Education. Journal of the History of Education Society 36, no. 2 (2007): 193-194.

MARGOLIS, Eric y Jeremy RowE. «Images of assimilation: photographs of Indian schools in Arizona». History of Education. Journal of the History of Education Society 33, no. 2 (2004): 199-230.

Mateos, Julio. «La marcha hacia la educación tecnocrática y de masas: sociedad y educación en España (1939-1970)». Dossier Educación de Revista de Andorra 11 (2012): 56-74.

Mattelart, Armand. La comunicación-mundo: historia de las ideas y de las estrategias. Madrid: Siglo XXI, 1996.

Mietzner, Ulrike, Kevin Myers y Nick Peim (eds.). Visual History. Images of Education. Bern: Peter Lang, 2005.

Milito Barone, Cecilia CRISTINA y Tamar Groves. «¿Modernización o democratización? La construcción de un nuevo sistema educativo entre el tardofranquismo y la democracia». Bordón 65, no. 4 (2013): 135-148.

Moreno, Pedro Luis. «Imágenes e historia de la educación popular: representaciones fotográficas de las Misiones Pedagógicas en la región de Murcia». Historia y Memoria de la Educación 5 (2017): 73-156.

NóvoA, Antonio. «Ways of Saying, Ways of Seeingx Public Images of Teachers (19th-20th Centuries)». Paedagogica Historica. International journal of the history of education 36, no. 1 (2000): 21-52. 
Olmos, Víctor. Historia de la Agencia EFE. El mundo en español. Madrid: Espasa Calpe, 1997.

ORTEGA, Félix. «La ideología de la reforma educativa de 1970». Revista de Educación no. extraordinario «La Ley General de Educación veinte años después» (1992): 31-46.

Pozo, María del Mar del. «Imágenes e Historia de la Educación: construcción, reconstrucción y representación de las prácticas escolares en el aula». Historia de la Educación. Revista Interuniversitaria 25 (2006): 291-315.

Pozo, María del Mar del y Teresa RabazAs. «Imatges fotogràfiques i cultura escolar en el franquisme: una exploració de l'arxiu etnogràfic». Educació $i$ Història. Revista d'història de l'educació 15 (2010): 165-194.

Puelles Benítez, Manuel de. "Tecnocracia y política en la reforma educativa de 1970». Revista de Educación, no. extraordinario «La Ley General de Educación veinte años después» (1992): 13-29.

- «Evolución de la educación en España durante el franquismo». En Historia de la Educación. Edad Contemporánea, editado por Alejandro Tiana, Gabriela Ossenbach y Florentino Sanz. Madrid: UNED, 2002.

- Política y educación en la España contemporánea. Madrid: UNED, 2011.

ROUSMANIERE, Kate. "Questioning the visual in the history of education». History of Education. Journal of the History of Education Society 30, no. 2 (2001): 109-116.

Rupérez Rubio, Paloma. «El Archivo Gráfico de la Agència EFE. Transición de un sistema manual a un sistema digitalizado: un análisis de la imagen». Cuadernos de documentación multimedia 6-7 (1998):351-361.

SANCHIDRIÁN, Carmen. «El uso de imágenes en la investigación histórico-educativa». RIE. Revista de Investigación Educativa 29, no. 2 (2011): 295-309.

SuREDA, Bernat y Gabriel BARCELó. «L'escola divulgada pel franquisme: el fons fotogràfic de l'Agència EFE». En Imatges de l'escola, imatge de l'educació, editado por Francisca Comas, Sara González, Xavier Motilla y Bernat Sureda, 277-288. Palma: Universitat de les Illes Balears, 2014.

SuREdA, Bernat, Xavier Motilla y Francesca Comas. «La revista Feminal: fotografía y visualización de la aportación femenina a la renovación educativa en Cataluña (1907-1917)». Historia de la Educación. Revista Interuniversitaria 33 (2014): 215-230.

TeJEDor, Concha. «El papel de los archivos en la sociedad de la información. El centro de documentación de la Agència EFE». En Documentación e poder na sociedade da información: o papel dos arquivos e os observatorios de comunicación, editado por Xosé López García y Rosa Aneiros Díaz, 67-78. Santiago de Compostela: Consello de Cultura Gallega, 2009. 
VeGA GIL, Leoncio. «Aproximación a la enseñanza secundaria durante el franquismo (1938-1967)». Historia de la Educación. Revista interuniversitaria 8 (1989): 29-44.

ViÑaO Frago, Antonio. «La educación general básica. Entre la realidad y el mito». Revista de Educación. La Ley General de Educación veinte años después, no. extraordinario (1992): 47-71.

- «Iconology and Education: Notes on the Iconographic Representation of Education and Related Terms». Paedagogica Historica. International journal of the history of education 36, no. 1 (2000): 75-92.

Wolf, Jacques. "Structure, fonctionnement et évolution du marché international des nouvelles. Les agences de presse de 1835 à 1934». Revue économique 42, no. 3 (1991): 575-601. 